\title{
Arctic Sea Ice Thickness Estimation Based on CryoSat-2 Radar Altimeter and Sentinel-1 Dual-Polarized SAR
}

\author{
Juha Karvonen $^{1}$, Eero Rinne ${ }^{1}$, Heidi Sallila ${ }^{1}$, Petteri Uotila ${ }^{2}$, and Marko Mäkynen ${ }^{1}$ \\ ${ }^{1}$ Finnish Meteorological Institute, PB 503, FI-00101, Helsinki, Finland \\ ${ }^{2}$ Institute for Atmospheric and Earth System Research / Physics, Faculty of Science, University of Helsinki, Finland
}

Correspondence: Juha Karvonen (juha.karvonen@fmi.fi)

\begin{abstract}
We present a method to combine CryoSat-2 (CS-2) radar altimeter and Sentinel-1 synthetic aperture radar (SAR) data to obtain sea ice thickness (SIT) estimates for the Barents and Kara Seas. Our approach yields larger spatial coverage and better accuracy compared to estimates based on either CS-2 or SAR alone. The SIT estimation method developed here is based on interpolation and extrapolation of CS-2 sea ice thickness (SIT) utilizing SAR segmentation and segmentwise SAR texture features. The SIT results are compared to SIT data derived from the AARI ice charts, to ORAS5. PIOMAS and TOPAZ4 ocean-sea ice data assimilation system reanalyses, and to daily MODIS based ice thickness charts. Our results are directly applicable to the future CRISTAL mission and Copenicus programme SAR missions.
\end{abstract}

\section{Introduction}

The goal of this study is to use Sentinel-1 (S-1) SAR data to inter- and extrapolate Cryosat-2 (CS2) sea ice thickness (SIT) estimates to spatially cover the whole Barents and Kara Sea area (see Fig. 1). Sea ice thickness (SIT) is an essential sea ice parameter. It is a key parameter, with sea ice concentration (SIC), for estimating total ice volume over any given area of interest. Accurate estimates of SIT are important for ice navigation, off-shore engineering and construction, climate studies as well as sea ice and weather forecasting. The ocean-atmosphere heat, mass, momentum, and gas exchanges are controlled by the sea-ice thickness distribution in the polar oceans. Thin ice with a thickness of less than half a meter produces strong heat and salt fluxes and affects the weather and deep water circulation in the polar oceans. Thick ice insulates the relatively warm ocean from the cold atmosphere maintaining the polar conditions, and is mainly responsible for the proportion of ice that persists through the summer melt period, which is particularly important for the summer radiation budget. For ship navigation in sea-ice-covered waters, the estimation of ice thickness is essential.

Estimation of ice thickness from radar and laser altimeter data has been studied extensively in recent years. Altimeters

onboard several satellites have provided estimates of sea ice thickness and volume time series and trends for the Arctic and Antarctic Oceans for recent decades. Such methods have been applied and evaluated e.g. in (Laxon et al. , 2003; Giles et al. , 2008; Kwok and Cunningham , 2008; Kwok et al. , 2009; Armitage et al. , 2015; Zygmuntowska et al. , 2014; Tilling et al. , 2015, 2018; Xia and Xie , 2018; Yi et al. , 2018; Xu et al. , 2020; Petty et al. , 2020). In this study we use the CryoSat-2 (CS-2) radar altimeter data (Wingham et al. , 2006). 
https://doi.org/10.5194/tc-2021-185

Preprint. Discussion started: 11 August 2021

(c) Author(s) 2021. CC BY 4.0 License.

\section{(c) (i)}

Due to the nature of altimeter measurements and the orbit pattern of the platform, CS-2 gives spatially and temporally sparse SIT information in temporal scales from one day to few weeks. Examples of all available CS-2 ice thickness estimates during the period of one day and one week over our Barents and Kara Seas study area are shown in Figure 1. From the viewpoint of tactical navigation these estimates are sparse, and the goal of our study is to develop a method to extrapolate altimeter SIT estimates between CS-2 ground tracks.

SIT algorithms combining CS-2 and other sources of information, e.g. SMOS (Soil Moisture and Ocean Salinity) mission with the the MIRAS (Microwave Imaging Radiometer using Aperture Synthesis) instrument exist (Ricker et al. , 2017). However, these algorithms still have relatively poor spatial and temporal resolution ( $25 \mathrm{~km}$, weekly estimates updated daily). Thus more algorithms fusing CS-2 data with data from instruments with higher spatial and temporal resolution are needed for timely high-resolution SIT estimates. Such ice thickness estimates can then be used e.g. in navigation and data assimilation to high-resolution ocean-sea ice forecast models.

Traditionally satellite altimeters, including CS-2, cannot estimate thickness of thin ice $(<0.5 \mathrm{~m})$ with reasonable uncertainty. Although recently launched ICESat-2 improves thin ice estimation, giving reasonable uncertainties down to SIT approximately $0.2 \mathrm{~m}$ (Petty et al. , 2020). Detection of thin ice and its thickness estimation can be done using satellite TIR imagery, e.g., from Moderate Resolution Imaging Spectroradiometer (MODIS), based ice surface temperature $\left(T_{s}\right)$ together with atmospheric forcing data through ice surface heat balance equation (Yu and Rothrock , 2016). Unfortunately, this method is restricted by cloud cover and quality of cloud masking in polar conditions (Frey at al. , 2008). A daily MODIS SIT chart combined from swath SIT charts, which mitigates the cloud problem, has been developed in (Makynen and Karvonen , 2017). In addition, daily cloud-cover corrected MODIS SIT composites for polynya monitoring have been produced utilizing several days of swath data (Paul et al. , 2015). Thin ice detection and its SIT estimation in winter conditions are also possible with microwave radiometer data. Thin ice thickness retrieval algorithms have been developed for low-frequency L-band brightness temperature (TB) data from SMOS and Soil Moisture Active Passive (SMAP) missions (Kaleschke et al. , 2012; Tian-Kunze et al. , 2014; Huntemann et al. , 2014; Kaleschke et al. , 2016; Schmitt and Kaleschke, 2018).

With the SMOS data SIT can be estimated up to 0.5-1.5 m thick ice (Kaleschke et al. , 2016). The drawback of the SMOS data is its poor spatial resolution, 35-50 km, which does not allow to detect leads and smaller polynyas. For high-frequency radiometer data (36 and $90 \mathrm{GHz}$ ), thin ice SIT retrieval algorithms have also been developed, e.g. (Martin et al. , 2004; Iwamoto et al. , 2014; Nakata et al. , 2019). The thin ice SIT can be typically estimated up to $20 \mathrm{~cm}$, and the SIT data are used for polynya monitoring, e.g. (Onshima et al. , 2016).

Estimation of SIT with synthetic aperture radar (SAR) data has been studied before. In the Baltic Sea, SIT estimation of deformed ice under dry snow conditions is possible through a statistical relationship between the ice freeboard and the radar backscatter (Simila et al. , 2016a). The standard deviation of the average large-scale surface roughness F, increases with increasing average $\mathrm{F}$, and, as the surface roughness increases, the backscatter also increases. An exponential empirical model was derived for estimating $\mathrm{F}$ from the backscattering coefficient $\left(\sigma^{0}\right)$ and dominant thickness of level ice. A good correlation between the L- and C-band co-polarization ratio and SIT of undeformed ice in the Sea of Okhotsk have been found (Nakamura et al. , 2006). The co-polarization ratio has little sensitivity to ice surface roughness and is related to variations in salinity, i.e. 
https://doi.org/10.5194/tc-2021-185

Preprint. Discussion started: 11 August 2021

(c) Author(s) 2021. CC BY 4.0 License.

\section{(c) (i)}

60 ice surface dielectric constant, that can be caused by changes in SIT (Wakabayashi et al., 2004). Toyota et al. (2011) found good correlation between ALOS/PALSAR L-band HH-polarization $\sigma^{0}$ and SIT $(\mathrm{R}=0.86)$ and surface roughness $(\mathrm{R}=0.70)$ in the seasonal ice zone (SIZ), and derived linear relation between $\sigma^{0}$ and SIT (SIT from 0.2 to $0.6 \mathrm{~m}$ ). They suggested that satellite L-band $\sigma^{0}$ data allows to estimate SIT distribution in the SIZ, where surface roughness is closely related with the SIT distribution through deformation processes. Airborne C-band polarimetric SAR (POLSAR) data together with a theoretical

65 backscattering model have been used to estimate SIT in the 0-10 cm range (Kwok et al., 1995). Zhang et al. (2016) derived SIT estimation method for undeformed first-year ice under dry snow conditions based on sea ice thermodynamic model and forward scattering model for C-band compact polarimetric (CP) SAR images. Using simulated CP imagery from RADARSAT2 POLSAR SIT estimation was possible up to $80 \mathrm{~cm}$ thickness. SAR data have also been used to estimate SIT of pancake ice from the way in which the pancake ice changes the dispersion relation of the waves, dampens the wave amplitude and causes

70 dissipation of the energy of the waves, i.e., it changes the wavelength of ocean waves as they enter the ice (Wadhams et al. 2018). SIT retrieval methods based only on the SAR data are still experimental, and no operational solutions are yet available.

\section{Study Area and Period}

Our study covers Kara and Barents Seas, see Fig. 2. Seasonal sea ice is found over most of our study area. In the far north, however, multi-year ice (MYI) is present year-round (Johannessen et al. , 2007). The average dates for the ice formation over the area varies from September 10:th in the north to mid-November in the southern Kara Sea and south-eastern Barents Sea (Pechora Sea), and March-April in the central Barents Sea (west of Novaya Zemlya) (Johannessen et al. , 2007). Melting season begins in late April in the marginal ice zone of the Barents Sea. By the end of June the central Barents Sea and the Pechora Sea are usually ice-free. In August the ice edge reaches Svalbard and Franz Josef Land. In the Kara Sea, melting gradually begins in May and continues through July and August. Most of the Kara Sea is ice-free between mid-July and mid-August. In Kara

80 Sea, the ice season lasts for 6-9 months depending on the location and seasonal conditions. We have only used wintertime data (January-April, October-December) for two years, 2016 and 2017. Currently, radar altimeter SIT retrieval is only possible in dry snow winter conditions (Kern et al., 2020). During the melt season the radar wave penetration in snow pack is ambiguous and surface type classification often fails due to melt ponds which give similar radar waveforms as the leads.

Throughout our study we use the following coordinate system (CS): polar stereographic projection with a center longitude 85 of $55^{\circ} \mathrm{E}$, reference latitude (latitude of the correct scale) of $70^{\circ} \mathrm{N}$ and the WGS84 datum. The upper left (UL) and lower right (LR) coordinates, i.e. the polar stereographic CS northing and easting in meters are: $\mathrm{UL}=(-700000,-1100000)$ and $\mathrm{LR}=(-$ 2550000,1100000). The size of the study area is $2200 \mathrm{~km}$ (easting) by $1850 \mathrm{~km}$ (northing).

\subsection{Weather Conditions}

Air temperature data $\left(T_{a}\right)$ from four coastal weather stations (Kongsøya, Vize, Im. M.V. Popova, and Varandey) shown in 2 90 to evaluate the weather conditions, periods of cold and warm weather, during our study period: January-April and OctoberDecember in 2016 and 2017. The daily average air temperure $\left(T_{a m}\right)$ from the four stations are shown in 3 . We set here $T_{a m}<-5$ 
https://doi.org/10.5194/tc-2021-185

Preprint. Discussion started: 11 August 2021

(c) Author(s) 2021. CC BY 4.0 License.

(c) (i)

${ }^{\circ} \mathrm{C}$ to represent dry snow cold conditions, and $T_{a m}>0{ }^{\circ} \mathrm{C}$ to moist/wet snow conditions where the snow pack, if exists, prevents or significantly attenuates radar returns from sea ice. Between these $T_{a m}$ limits the state of the ice pack is ambiguous as it depends on $T_{a}$ history and time of the CS-2 and S-1 data acquisition, e.g. early morning vs. late afternoon. The $T_{a m}$ data will not be used classify the CS-2 and S-1 into different weather condition classes, but to support analysis on the accuracy of SIT from the combined CS-2 and S-1 data. It is noted that the $T_{a m}$ limits above are only approximations.

At the Vize station, representing the northern part of the Kara Sea, $T_{a m}$ during Janury-April 2016 is mostly below $-5{ }^{\circ} \mathrm{C}$, there is only few instances of one to three day long periods of $T_{a m}$ above $-5^{\circ} \mathrm{C}$, and $-T_{a m}$ is all the time below $0{ }^{\circ} \mathrm{C}$. $T_{a m}$ at the Popova station, which is located at the central Kara Sea, has similar behaviour, but from around 21 Apr onwards $T_{a m}$ is over $-5{ }^{\circ} \mathrm{C}$. At the Kongsøya station located on the Barents Sea, east of Svalbard, $T_{a m}$ is much warmer and is below $-5^{\circ} \mathrm{C}$ only during half of the days in January-April, but still $T_{a m}$ is over $0{ }^{\circ} \mathrm{C}$ only in the beginning of Jan. At the Varandey station in the Pechora Sea $T_{a m}$ shows very cold weather in Jan, short periods of $T_{a m}>-5{ }^{\circ} \mathrm{C}$ in Feb and Mar, and then rather warm weather after first week of Apr. We estimate that the period Jan-Apr 2016 represent typically cold dry snow conditions in our study area.

During October 2016 to Apr $2017 T_{a m}$ from the Vize station is over $0{ }^{\circ} \mathrm{C}$ during the first week of October and mostly over $-5{ }^{\circ} \mathrm{C}$ up to end of third week of November. After that there is only few cases of 1-3 day long periods of $T_{a m}$ above $-5{ }^{\circ} \mathrm{C}$. At the Popova station $T_{a m}$ is over $0{ }^{\circ} \mathrm{C}$ during first two weeks of October, and mostly below $-5{ }^{\circ} \mathrm{C}$ after beginning of November. The Kongsøya $T_{a m}$ is all the time over $-5^{\circ} \mathrm{C}$ up to 24 November, and afterwards there are variable periods of $T_{a m}$ above and below $-5{ }^{\circ} \mathrm{C}$ with an average decreasing $T_{a m}$ trend. $T_{a m}$ is all the time below $-5{ }^{\circ} \mathrm{C}$ in Apr. At the Varandey station $T_{a m}$ is above $0{ }^{\circ} \mathrm{C}$ up to end of October. After beginning of November $T_{a m}$ is mostly below $-5^{\circ} \mathrm{C}$. There is a period of warm weather in 15-26 Mar with $T_{a m}$ sometimes being slightly over $0{ }^{\circ} \mathrm{C}$. We conclude that CS- 1 and S-1 data from the beginning of October to roughly mid-November is typically affected by wet or moist snow conditions, depending on the diurnal acquisition time and location in our study area (more probable in the Barents and Pechora Seas). Data acquired from mid-November 2016 to Apr 2017 mostly represent cold winter conditions.

In October - December 2017 the Vize $T_{a m}$ is continously below $-5{ }^{\circ} \mathrm{C}$ after 5 November. It is never above $0{ }^{\circ} \mathrm{C}$. At the Popova station $T_{a m}$ very close to or above $0{ }^{\circ} \mathrm{C}$ during first two weeks of October. It is mostly below $-5^{\circ} \mathrm{C}$ after 7 November. In the Barents Sea at the Kongsøya stations $T_{a m}$ is longer periods below $-5^{\circ} \mathrm{C}$ only in 20-30 November, and 25 Dec onwards. At the Varandey station $T_{a m}$ is above $0{ }^{\circ} \mathrm{C}$ in $1-10$ October, and continously above $-5{ }^{\circ} \mathrm{C}$ up to 7 November. Afterwards there are periods up to 10 days with $T_{a m}$ either above or below $-5{ }^{\circ} \mathrm{C}$. It seems that in the Kara Sea the time period after first week of November 2017 can be assumed to represent mostly cold winter conditions. In the Barents and Pechora Seas in November and Dec there are also periods of cold winter conditions, but sometimes $T_{a m}$ is between -5 and $0{ }^{\circ} \mathrm{C}$, when there could have been moist snow effects on the radar signatures.

\section{Data}

In this section we present the data sets used in our study. 
https://doi.org/10.5194/tc-2021-185

Preprint. Discussion started: 11 August 2021

(c) Author(s) 2021. CC BY 4.0 License.

(c) (i)

\subsection{CryoSat-2 Data}

CS-2's primary payload is the Synthetic Aperture Interferometric Radar Altimeter operating in the Ku-Band (13.6 GHz) which allows a much smaller sampling footprint (about $250 \mathrm{~m}$ in the satellite track direction) than earlier satellite radar altimeters. Over sea ice, CS-2 echoes are assumed to scatter from the interface between the ice surface and the layer of overlying snow (Laxon et al. , 2013), thus enabling freeboard estimation, and further, sea ice thickness calculation by known snow depth and density.

The quantity altimeters measure is surface elevation, from which freeboard $(F)$ can be derived from. Assuming hydrostatic equilibrium and known sea ice density $\left(\rho_{i}\right)$, snow density $\left(\rho_{s}\right)$ and water density $\left(\rho_{w}\right)$ the following equation can be formed:

$$
h_{i}=\frac{\rho_{w}}{\rho_{w}-\rho_{i}} F-\frac{\rho_{w}-\rho_{s}}{\rho_{w}-\rho_{i}} h_{s} .
$$

As can be seen from equation above, snow estimate has a large effect on retrieved SIT. In the case of radar altimeters, such as CS-2 used here, $h_{s}$ is also required for signal propagation speed correction in deriving $F$. A more detailed analysis on the effect of snow can be found in (Kern et al., 2015). In this study, like in many other CS-2-based sea ice thickness products, climatological snow depth and density based on the Warren climatology (Warren et al. , 1999) are used.

In this study we have computed sea ice thickness with FMI implementation of the python sea-ice radar altimetry toolbox (PySiral, available in: https://github.com/shendric/pysiral). The primary input has been the European Space Agency's CS-2 Baseline-C Level-1B product. Our processing follows the algorithm of (Ricker et al. , 2014; Hendricks et al. , 2016). For auxilliary data we have used the DTU15 mean sea surface height product, EUMETSAT OSISAF sea ice concentration and sea ice type, as well as Warren 1999 snow depth and density data with the 50 percent reduction over first-year ice first proposed by (Kurtz and Farrell , 2011).

\subsection{Sentinel-1 SAR}

All the available Copernicus Sentinel-1 (S-1) C-band dual-polarized Extra Wide (EW) swath mode level 1 Ground Range Detected Medium resolution (GRDM) data with the HH/HV polarization channels over the study area and period (January-April and October-December 2016, and January-April and October-December 2017) were used in this study. The SENTINEL-1 SAR data are publicly available through the European Space Agency (ESA) Copernicus Science Hub (https://scihub.copernicus.eu/).

\subsection{Reference Data}

In our study we use the Russian AARI ice charts, ORAS5, PIOMAS, and TOPAZ4 ocean-sea ice reanalyses SIT data, and MODIS daily SIT charts as reference data. They are used to evaluate the performance of our CS2-SAR SIT estimation method. The TOPAZ4 SIT model data are also used to remap the CryoSat-2 training data set based on cumulative SIT distributions. 
https://doi.org/10.5194/tc-2021-185

Preprint. Discussion started: 11 August 2021

(c) Author(s) 2021. CC BY 4.0 License.

(c) (i)

\subsubsection{AARI ice charts}

Arctic and Antarctic Research Institute (AARI) produces weekly ice charts for the Barents and Kara Seas (Bushuev et al. , 2007). The ice charts are based on the available visible, thermal infrared and SAR imagery and reports from coastal stations and ships. The polygonalization of images and subsequent interpretation and mapping of ice conditions are carried out by skilled ice analysts. The main purpose of the weekly ice chart is to show the spatial distribution and characteristics of sea ice. Many sea ice details within polygons are ignored. The AARI ice charts are in the digital SIGRID-3 vector file format (JCOMM , 2014b). We have not found any publication that discusses the uncertainty of the AARI weekly ice chart. The AARI ice charts are available at: http://wdc.aari.ru/datasets/d0004/.

The ice charts convey their information in codes that are explained in (JCOMM , 2014a). The charts show total concentration (code CT) and partial concentrations of the first, second, and third thickest ice (codes CA, CB, and CC) along with their respective stages of development (SA, SB, and SC) and form of ice (FA, FB, FC) for polygonal areas of variable sizes. The concentrations are shown with intervals of either one or two tenths wide. The stage of development is defined as ice thickness intervals. Following thickness ranges are used: nilas $(<10 \mathrm{~cm})$, young ice $(10-30 \mathrm{~cm})$, grey ice $(10-15 \mathrm{~cm})$, grey-white ice $(15-30 \mathrm{~cm})$, thin FYI $(30-70 \mathrm{~cm})$, medium FYI $(70-120 \mathrm{~cm})$, thick FYI $(>=120 \mathrm{~cm})$, FYI in general $(>=30 \mathrm{~cm})$, and old ice $(>=120 \mathrm{~cm})$. The form of ice carries information on e.g. ice floe size or occurrence of landfast ice. Some polygons only have one or two stage of development classes assigned to them (i.e. polygons are more homogenous).

In the ice charting community, the definition of ice thickness that the ice charts reports is somewhat ambiguous. For the AARI charts, (Afanasyeva et al., 2019) states that: "Fast ice thickness measured at a hydrometeorological station serves as a reference. Looking at a satellite image, ice expert matches brightness of drifting ice outside the shore to brightness of land-fast ice with known thickness." Thus, we interpret the AARI ice thickness as the thickness of level ice in the area - analogous to the thermodynamic grown fast ice.

For validation, polygons from AARI charts were gridded to $1 \mathrm{~km}$ by $1 \mathrm{~km}$ grid covering our study area. Then for each AARI ice chart polygon a mid-range SIC and mid-range SIT or upper or lower SIT values of the first, second, and third thickest ice types were assigned. However, for FYI general type a SIT value of $95 \mathrm{~cm}$ is used (same as for thick FYI). An average SIT for each chart polygon was calculated as a sum of the SIT values for the three ice types weighted with their concentrations. Finally, the gridded charts for the Barents and Kara Seas were combined together, see an example in Fig. 8(c). This processing of the AARI charts has been used previously by (Makynen and Karvonen , 2017). The total number of the AARI weekly charts used in the validation was 37 (time span from 4 Jan until 26 Dec, excluding the summer period) for both the Barents and Kara Seas.

\subsection{Model Reanalysis Data}

\subsubsection{TOPAZ4}

TOPAZ4 is a coupled ocean-sea ice model with advanced data assimilation system for the North Atlantic Ocean and Arctic (Sakov et al. , 2012). The data assimilation is based on the use of ensemble Kalman filter (Evensen , 1994). The resolution of the TOPAZ4 model grid is $12-16 \mathrm{~km}$. TOPAZ4 is operationally available in CMEMS (Copernicus Marine Environment 
https://doi.org/10.5194/tc-2021-185

Preprint. Discussion started: 11 August 2021

(c) Author(s) 2021. CC BY 4.0 License.

(c) (i)

Monitoring Service) funded by European Commission. In this study we have used the TOPAZ4 daily reanalysis ice thickness values (CMEMS product ARCTIC_REANALYSIS_PHY_002_003) (Copernicum PUM , 2020). The CS2SMOS thickness (Ricker et al. , 2017), based on fusion of Cryosat-2 and SMOS SIT is assimilated to the TOPAZ4 reanalysis SIT product. The modelled sea-ice thickness provided by the TOPAZ4 CMEMS product is a diagnostic variable based on prognostically calculated sea-ice volume divided by sea-ice concentration for each model grid cell. Accordingly, it provides the mean sea-ice thickness for the portion of grid cell that is covered by sea ice.

\subsubsection{ORAS5}

Because TOPAZ4 seems to underestimate the Arctic ice thickness (Xie et al. , 2018), we also used the ORAS5 reanalysis SIT data (Zuo et al. , 2017, 2019). Tietsche et al. (2017) calculated the root-mean-square-difference between ORAP5, the prototype of ORAS5, and ICESat sea-ice thicknesses to be of $1.0 \mathrm{~m}$, comparable to the PIOMAS product (Schweiger et al. , 2011), see also section 3.4.3. The ORAS5 data are produced by the European Centre of Medium-Range Weather Forecasts (ECMWF) in 0.25 degree nominal resolution in a stretched global tri-polar grid with the poles in northern Canada, Eurasia and the South Pole. This grid has a resolution of about $5-15 \mathrm{~km}$ in the Arctic. A feature of ORAS5 is that in the open-water part of a grid cell sea ice forms at a certain initial thickness of the order of $H_{0}=0.5 \mathrm{~m}$ (Tietsche et al. , 2017). Such a treatment of initial sea ice is common in geophysical sea-ice models (Lemieux et al. , 2018). The initial thickness $H_{0}$ is, coincidentally, close to the thinnest ice CS2 is able to reliably measure. As TOPAZ4, the ORAS5 product provides the diagnostic sea-ice thickness for each grid cell that has been calculated by dividing the modelled sea-ice volume by concentration.

\subsubsection{PIOMAS}

Additionally we utilized the PIOMAS model (Zhang and Rothrock, 2003) SIT data which have a coarser resolution than TOPAZ4 and ORAS5. Despite the coarse resolution, PIOMAS sea-ice volume agrees well with the ICESat estimates (Schweiger et al. , 2011). The PIOMAS model grid is a stretched generalized orthogonal curvilinear coordinate (GOCC) system. A GOCC system allows a coordinate transformation that displaces the pole of the model grid. The PIOMAS model data are in the GOCC grid with the northern grid pole displaced into Greenland. The PIOMAS resolution in our study area is around $40 \mathrm{~km}$. Unlike TOPAZ4 and ORAS5, PIOMAS provides sea-ice volume per unit area, which was divided by the PIOMAS sea-ice concentration to obtain sea-ice thickness per grid cell. Because of the coarse resolution of the PIOMAS data we did not use it in direct comparisons, but we utilise it in defining the mapping of CS2 thicknesses to model compliant thicknesses in Section 3.

\subsection{MODIS Daily SIT Chart}

Daily MODIS ice thickness $\left(h_{i M}\right)$ charts for our study area have been processed for two winters, from November 2015 to April 2017. All the details on the daily chart processing can be found in (Makynen and Karvonen , 2017). The daily charts are

215 based on all available Aqua and Terra MODIS $h_{i M}$ swath charts. Charts for very cloudy days were manually excluded. The total number of the daily charts is 317 . 
The MODIS based SIT charts have pixel size of $1 \mathrm{~km}$, but the cloud mask has $10 \mathrm{~km}$ pixel size. The daily $h_{i M}$ chart shows daily median $h_{i M}\left(h_{i M}^{d}\right)$ for pixels which had at least two $h_{i M}$ samples from the swath charts. The requirement for having at least two valid $h_{i M}$ samples decreases the errors due to the misdetected clouds in the swath charts. $h_{i M}^{d}$ has following values: 0-0.3 m, $0.4 \mathrm{~m}$ marking $h_{i M}^{d}$ class of 0.31-0.5 m which corresponds to thin FYI of the first stage in the WMO sea ice nomenclature (JCOMM , 2014a), and $0.5 \mathrm{~m}$ for $h_{i M}^{d}>0.5 \mathrm{~m}$.

The MODIS $h_{i M}$ swath charts are based on ice surface temperature from the MODIS/Terra or Aqua Sea Ice Extent 5-Min L2 Swath $1 \mathrm{~km}$ product (MOD29/MYD29) and ERA-Interim atmospheric forcing data. The processing method of the $h_{i M}$ swath chart is described in detail in (Makynen et al. , 2013). Cloud masking for the swath $h_{i M}$ charts was conducted using fully automatic methods (Makynen and Karvonen , 2017). As the uncertainty of the retrieved $h_{i M}$ increases with increasing air temperature $T_{a}$, the $h_{i M}$ retrieval with the MODIS swath data was not conducted when $T_{a}>-5{ }^{\circ} \mathrm{C}$. The typical maximum reliable $h_{i M}$ (max 50\% uncertainty) is 0.35-0.50 m (Makynen et al. , 2013).

\section{Methodology}

\subsection{S-1 preprocessing}

We georectified and sampled the S-1 SAR data into a 100-m pixel size. Absolute calibration was applied to get the backscattering coefficient value at each pixel in logarithmic scale (unit $\mathrm{dB}$ ). The calibration to provide the backscattering coefficients ( $\sigma_{H H}^{0}$ and $\sigma_{H V}^{0}$ for HH- and HV-channel) at image location (pixel i) was performed according to the following equation (Bourbigot et al. , 2016):

$$
\sigma_{i}^{0}=\frac{\left(D N_{i}^{2}-n_{i}\right)}{A_{i}^{2}}
$$

$D N_{i}$ is the original image pixel value at location i, $n_{i}$ is the provided noise data at location $\mathrm{i}$,and $A_{i}$ the provided calibration coefficient at location i.

The S1 data was preprocessed by applying a linear incidence angle correction (Makynen and Karvonen , 2017) to the HH channel and a combined incidence angle and noise floor correction to the HV channel, for details, see (Karvonen , 2017). The $\mathrm{HH}$ channel incidence angle correction has been tuned for sea ice. This leads to reduced performance on open water because of the varying contribution of the water surface due to waves (Bragg scattering) to the backscattering measured by SAR. After incidence angle and noise floor corrections the image data were geo-rectified into the polar stereographic projection specified in Section 2. After geo-rectification the imagery were down-sampled to $500 \mathrm{~m}$ resolution, and finally the daily mosaics were constructed by overlaying the newer images over the older ones such that at each mosaic grid cell (pixel) the newest SAR data prior to the mosaic time label, which was defined to be 12:00 UTC daily here, was available.

The mosaic was initialized only in the beginning of the mosaicking (in this case in the beginning January 2016). In practice the data at a given grid cell location were never older than three days from the mosaic time label. Separate mosaics for $\mathrm{HH}$ and HV channels were constructed. A land mask based on the GSHHG coastline (Wessel and Smith, 1996) was applied to 
https://doi.org/10.5194/tc-2021-185

Preprint. Discussion started: 11 August 2021

(c) Author(s) 2021. CC BY 4.0 License.

(c) (i)

the mosaics to exclude land areas. The SAR mosaics of 21 February 2017 for HH and HV channels are shown in Fig. 4 and a detail of the channel images in Fig. 5.

SAR images were processed to 8 bpp images by scaling the $\sigma^{0}$ between 1 and 255 ( 0 representing background). The scaling for the $\mathrm{HH}$ channel is such that $-30 \mathrm{~dB}$ corresponds to the pixel value of one and $0 \mathrm{~dB}$ corresponds to the pixel value of 255 . For HV channel the decibel values are -40 and 0 , respectively. For segmentation the meanshift algorithm (Fukunaga and Hostetler, 1975) was first applied to locate the modes of the two-dimensional (HH and HV) SAR data. The meanshift algorithm has been empirically adjusted so that about 10-15 modes will be produced after convergence. The initial 10-15 categories based on MS were then used as a starting point for iterated conditional modes (ICM) segmentation (Besag , 1986).

\subsection{Interpolation of CS2 using S-1 SAR}

First, the SAR mosaics are segmented. Next, the CS-2 SIT values are mapped to SAR segments where enough CS-2 SIT measurements are available. Then the SIT is estimated for the rest of the segments by using a difference function describing the similarity of the segments and pairwise distance of each pair of segments in time and space. The difference function includes several SAR features in addition to the temporal and spatial distance of the segments. The data of January-April and October-December 2016 were used for training the algorithm and January-April and October-December 2017 data were used for evaluating the algorithm performance.

A block diagram of the algorithm is presented in Fig. 6. In the first phase the CS-2 SIT values are assigned to SAR segments of the segmented SAR mosaic. In the next phase the difference function is computed for all the segments without an assigned SIT value yet between all the segments with an already assigned SIT value within range. In the following phase a SIT is assigned to the segments without a SIT value using a median of SIT values of M segments with the smallest difference function values. As a last step, a remapping based on histograms of the estimated SIT and PIOMAS, ORAS5 and TOPAZ4 model reanalyses SITs for the training data are performed to get a bias-corrected SIT estimate for each segment.

The SAR features were computed within a round-shaped window with a radius $\mathrm{R}$. In this study we have used $\mathrm{R}=5$ pixels. Median of the feature values within each segment were then assigned to the segments as segment-wise texture features. The features used in this study are:

- $\mathrm{HH}$ backscattering coefficient $\left(\sigma_{H H}^{0}\right)$

- HV backscattering coefficient $\left(\sigma_{H V}^{0}\right)$

- HH coefficient of variations $\left(F_{v}\right)$

- HV coefficient of variations $\left(F_{v}\right)$

- HH local autocorrelations $\left(C_{A}\right)$

- HV local autocorrelations $\left(C_{A}\right)$

- HH entropies ( $E$ ) 
https://doi.org/10.5194/tc-2021-185

Preprint. Discussion started: 11 August 2021

(c) Author(s) 2021. CC BY 4.0 License.

(c) (1)

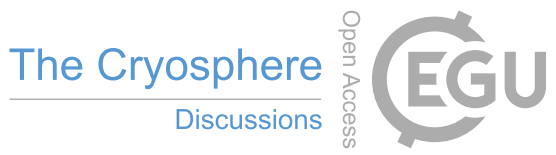

- HV entropies $(E)$

- HH local variogram slopes $\left(V_{1}\right)$

- HV local variogram slopes $\left(V_{1}\right)$

- HH edge point densities $\left(D_{E}\right.$ and $\left.D_{C}\right)$

- HV edge point densities $\left(D_{E}\right.$ and $\left.D_{C}\right)$

- HH corner point densities $\left(D_{E}\right.$ and $\left.D_{C}\right)$

- HV corner point densities $\left(D_{E}\right.$ and $\left.D_{C}\right)$

- $\mathrm{HH} / \mathrm{HV}$ channel cross-correlation $\left(C_{c}\right)$

The feature computation windows were overlapping by half of the window size (i.e. window radius) in the both the coordinate directions.

Entropy $E$ (Shannon, 1948) was computed as

$$
E=-\sum_{k=0}^{255} p_{k} \log ^{2} p_{k}
$$

where $p_{k}$ 's are the proportions of each gray tone $k$ within each computation window. Auto-correlation $C_{A}$ (Box and Jenkins, 1976) was computed as

$$
\begin{gathered}
C_{A}(k, l)= \\
\frac{\sum_{i j \in W}\left(I(i-k, j-l)-\mu_{W}\right)\left(I(i, j)-\mu_{W}\right)}{|B| \sigma_{W}^{2}},
\end{gathered}
$$

where $I(k, l)$ is the pixel value at image location $(\mathrm{k}, \mathrm{l})$. Mean over the horizontal, vertical and diagonal directions i.e. $(k, l)=$ $(0,1),(k, l)=(1,0),(k, l)=(1,1)$ and $(k, l)=(1,-1)$ was used to accomplish directional independence. The computation window is here denoted by W. $\sigma_{W}$ and $\mu_{W}$ are the mean and standard deviation within the window, respectively.

The cross-correlation $C_{c}$ (Knapp and Carter , 1976) between the SAR polarization channels (HH and HV,) here denoted by $X(\mathrm{HH})$ and $Y(\mathrm{HV})$, is

$$
\begin{gathered}
C_{c}(k, l)=\frac{1}{N_{p} \sigma_{x} \sigma_{y}} \times \\
\sum_{i, j \in W}\left(X(k+i, l+j)-\mu_{y}\right)\left(Y(k+i, l+j)-\mu_{y}\right),
\end{gathered}
$$

where $\mathrm{k}$ and 1 refer to the row and column coordinates of the window centre image pixel, respectively, $\sigma_{x}$ and $\mu_{x}$ are the mean and standard deviation, respectively, of the window in $X$ and $\sigma_{y}$ and $\mu_{y}$ are the mean and standard deviation, respectively, of the window in $Y . N_{p}$ is the number of pixels within the window denoted by $W$. 
We also computed texture features based on local variograms. The variograms were locally estimated in a window with a radius of five pixels. Assuming a stationary and isotropic process, the variogram $\gamma$ is (locally) dependent on the inter-distance, here denoted by h, only (Cressie , 1993), and can be estimated as

$$
\gamma(h)=\frac{1}{2\left|H_{h}\right|} \sum_{i, j \in N_{h}}\left|z_{i}-z_{j}\right|^{2},
$$

where $z_{i}$ and $z_{j}$ are the pixel values at locations $\mathrm{i}$ and $\mathrm{j}$, whose distance is $\mathrm{h}$. We have computed the length of approximately linear part of the variogram as a function of $\mathrm{h}$, and the slope of a linear fit of this linear part of the variogram. These are referred here as features $V_{1}^{c h}$ and $V_{2}^{c h}$, where ch (channel) is either HH or HV.

The coefficient of variation is computed as

$$
C_{v}=\sigma_{w} / \mu_{w}
$$

where $\sigma$ and $\mu$ are the standard deviation and mean within the window $w . C_{v}$ is computed separately for the HH and HV channels, respectively, i.e. we have $C_{v}^{H H}$ and $C_{v}^{H V}$.

The edge and corner points counts $\left(N_{e}\right.$ and $\left.N_{c}\right)$ were extracted for each segment using local binary patterns (Ojala et al. , 1996) in a similar way as presented in (Karvonen, 2016). The proportion of the number of edge and corner points w.r.t. each segment area (in pixels) was computed for both polarization channels and they were used as texture features. These features are denoted here by $N_{e}^{H H}, N_{e}^{H V}, N_{c}^{H H}$ and $N_{c}^{H V}$.

Based on the segmentation result and the SAR texture features complemeted by $\sigma_{H H}^{0}$ and $\sigma_{H V}^{0}$ the segment-wise median values of each texture feature and channel-wise SAR backscatterting coefficients were calculated, resulting to a total of 15 SAR features (13 texture features and two backscattering coefficients) for each segment. As an example of the segmentation the segmentation result of the SAR mosaic of 21 February 2017 with $\sigma_{H H}^{0}$ and $\sigma_{H V}^{0}$ medians assigned to SAR segments is shown in Fig. 3 and a detail of these HH and HV channel figures in Fig. 4. We use the SIT estimation and reference SIT data of this day as an example in the following sections.

According to our analysis the SIT difference between two segments was mainly explained by L1 difference of a few features $\left(\sigma_{H V}^{0}, \mathrm{HV}\right.$ entropy and $\mathrm{HH}$ edge density) and the spatial distance between segment means, based on a least squares fit of the training data (Jan-Apr and Oct-Dec 2016), but other features also had minor effect. For this reason we have used all the abovementioned features in our difference function because the number of features did not produce any computational problems with respect to execution time or hardware resources on a common desktop personal computer.

The 2016 (January-April, October-December) CS-2 and SAR data were used for training and 2017 (January-April, OctoberDecember) data for testing the method. The segment difference function $T$ was defined as linear combination of the SAR feature differences and temporal and spatial distance between as segment pair:

$$
T=c_{t} \Delta t+c_{d} \Delta D+\sum_{k=1}^{N_{f}} c_{k}\left|\Delta f_{k}\right|
$$

$\Delta t$ is the (absolute) time difference in days, $\Delta D$ is the distance difference between the centres of the segments, $\Delta f_{k}$ is the difference between the SAR feature $f_{k}(k=1, \ldots, 15)$ of the two segments in comparison. 2016 CS-2 thickness and SAR 
https://doi.org/10.5194/tc-2021-185

Preprint. Discussion started: 11 August 2021

(c) Author(s) 2021. CC BY 4.0 License.

(c) (i)

mosaics were used in defining the coefficients $c_{t}, c_{d}, c_{k}$, using a non-negative least squares (LS) fit. Non-negative LS was used because all the absolute differences should have an increasing effect on $T$.

As training data we used the CS-2 SIT values assigned to the segments. Each 2016 training data SAR segment with an assigned SIT were included and the neighboring assigned SIT values and the corresponding segment pair-wise feature differences were used in the LS fit, i.e. each segment pair with an assigned CS-2 SIT were utilized.

SIT for a segment (S) without a SIT value were obtained as follows: $\mathrm{T}$ between $\mathrm{S}$ and all the other segments within a predefined range was computed and the median of the SIT values corresponding to the $M$ segments with the smallest values of $\mathrm{T}$ within a predefined spatio-temporal search range was assigned to segment $\mathrm{S}$ SIT. The spatio-temporal search range was 10 days in time (for natural reasons only backwards) and $1000 \mathrm{~km}$ (2000 pixels) in range. We have used parameter values of $\mathrm{N}=9$ and $\mathrm{M}=5$ in this study.

\subsection{Ice chart and model compliant CS2 product}

Because SIT was significantly overestimated for the 2016 training data, we introduce a mapping based on ORAS5 and PIOMAS model reanalysis data to reduce the SIT overestimation. The CS-2 SIT measurements were further mapped, based on the training data of 2016 and the corresponding PIOMAS reanalysis SIT in the range 0-200 cm of CS-2. The coarser resolution PIOMAS data were selected for this purpose because ORAS5 does not give reasonable SIT values for SIT less than $50 \mathrm{~cm}$ (Tietsche et al. , 2017). Above $200 \mathrm{~cm}$ a linear fit to the linear part (up to $350 \mathrm{~cm}$ ) of the ORAS5 SIT histogram correspondence was used because from about $200 \mathrm{~cm}$ ORAS5 indicates thicker ice and the problem with ice model reanalysis data has been underestimation of SIT. Also ORAS5 SIT starts to saturate above $350 \mathrm{~cm}$ and this part of the matching was not used in the mapping and the mapping above $350 \mathrm{~cm}$ uses the same linear slope defined for the interval $200-350 \mathrm{~cm}$. The histogram mapping is based on the normalized histograms and minimizing the Kolmogorov-Smirnov distance (i.e. mapping the cumulative histograms) of the CS-2/S-1 SIT and the TOPAZ4 reanalysis SIT. The Kolmogorov-Smirnov distance, $D_{m}$, for a variable $\mathrm{x}$ is also defined as

$$
D_{m}=\sup _{x}\left|F_{t}(x)-F_{c}(x)\right|,
$$

where $\sup _{x}$ is the supremum within the range of $\mathrm{x}$ (SIT in our case) and $F_{t}(x)$ and $F_{c}(x)$ are the cumulative probability density functions (CDF's) of the ORAS5 or PIOMAS SIT, and CS-2 SIT computed for the 2016 training data set. In our case we have quantized the SIT into integer centimeters and the SIT histograms are used as approximations of probability density functions (PDF's). The SIT values were quantized to $1 \mathrm{~cm}$ accuracy and 16 bits.

This mapping based on the 2016 training data CS-2 SIT and 2016 model SIT is shown in Fig. 7 as a red curve, until 200 $\mathrm{cm}$ it follows the PIOMAS mapping and above $200 \mathrm{~cm}$ a linear fit to ORAS5. For reference also the Topaz4 matching result is shown in the Figure as a green curve. It can be seen that Topaz4 reanalysis SIT mapping is at significantly lower level than the mapping for the other two models. 


\section{Results}

We have compared the SIT values produced by the algorithm to the SIT based on the AARI ice charts, ORAS5, PIOMAS and TOPAZ4 reanalysis SITs to evaluate the performance of the SIT estimation. In the comparisons we have used the following measures of difference between the SIT estimates and the reference SIT:

$$
\begin{gathered}
C=\frac{1}{N_{s} \sigma \sigma_{\text {ref }}} \sum_{i=1}^{N_{s}}\left(\left(X_{i}-\mu\right)\left(X_{i}^{\mathrm{ref}}-\mu_{\text {ref }}\right)\right), \\
D_{L 1}=\frac{1}{N_{s}} \sum_{i=1}^{N_{s}}\left|X_{i}-X_{i}^{\mathrm{ref}}\right| \\
D_{\mathrm{sgn}}=\frac{1}{N_{s}} \sum_{i=1}^{N_{s}}\left(X_{i}-X_{i}^{\mathrm{ref}}\right) . \\
D_{\mathrm{RMS}}=\sqrt{\frac{1}{N_{s}} \sum_{i=1}^{N_{s}}\left(X_{i}^{\mathrm{est}}-X_{i}^{\mathrm{ref}}\right)^{2}} .
\end{gathered}
$$

$N_{s}$ refers to the number of samples (number of grid points) used in the comparison and $X_{i}\left(i=1 \ldots N_{s}\right)$ are the estimated values of SIT and $X_{i}^{\text {ref }}$ are the values of the reference SIT data at the same location as $X_{i}$. $C$ is the correlation, $D_{L 1}$ is the L1 difference and $D_{s g n}$ is the signed L1 difference giving the estimation bias, positive bias indicating overestimation and negative bias indicating underestimation. $D_{R M S}$ is the root-mean-square difference. $\mu$ and $\mu_{r e f}$ are the means of the estimated SIT and reference SIT, and $\sigma, \sigma_{r e f}$ are the standard deviations of the estimated SIT and reference SIT, respectively.

On average the correlation between the non-interpolated CS-2 SIT estimates and AARI SIT was 0.22. Correlation between CS-2 SIT and the two model SIT (TOPAZ4 and ORAS5) were 0.18 and 0.12 respectively. The L1 difference and bias of the CS-2 SIT w.r.t. AARI SIT were $50 \mathrm{~cm}$ and $35 \mathrm{~cm}$, CS-2 showing thicker ice. The L1 difference and bias of the CS-2 SIT w.r.t. TOPAZ4 reanalysis SIT were $53 \mathrm{~cm}$ and $31 \mathrm{~cm}$, again CS-2 being thicker. The corresponding numbers w.r.t. ORAS5 SIT were $49 \mathrm{~cm}$ and $0 \mathrm{~cm}$. Interestingly, for the ORAS5 which initiates its ice thickness at $50 \mathrm{~cm}$ has zero bias against the CS-2 estimates.

The correlations for the CS-2 SIT assigned to SAR segments was somewhat higher, around 0.35. The correlations w.r.t. the two reference data sets for each 2017 winter month and their averages and standard deviations are presented in Table I, the corresponding L1 differences in Table II, the biases in Table III and the RMSD's in Table IV. Also the differences and correlations between the three reference SIT data sets are shown in Table V. CS-2 in the tables refers to the CS-2 data mapped to the segments with more than $N$ CS-2 measurements available.

The monthly cross-correlations between the estimated SIT and the estimated remapped SIT w.r.t. AARI SIT were quite similar with values around 0.3-0.4 during the winter months (January-April, December). For the freeze-up months (OctoberNovember) the cross-correlation w.r.t. AARI SIT were higher, up to about 0.7 in October and about 0.45 in November. This is explained by the thinner ice and smaller deviation in ice thickness. The same phenomena can be seen in the cross-correlations 
https://doi.org/10.5194/tc-2021-185

Preprint. Discussion started: 11 August 2021

(c) Author(s) 2021. CC BY 4.0 License.

\section{(c) (i)}

w.r.t. TOPAZ4 and ORAS5 SIT. Also warm weather and thin moist snow cover may have an effect to the results in October and November.

The cross-correlation of the estimated SIT and remapped estimated SIT w.r.t. AARI SIT and TOPAZ4 reanalysis SIT were similar both monthly and on average. The average cross-correlations w.r.t. AARI SIT were 0.37 for the estimated SIT and 0.39 for the remapped estimated SIT. The corresponding values w.r.t. TOPAZ4 reanalysis SIT were 0.39 and 0.42 , and w.r.t. ORAS5 SIT 0.35 and 0.39. The minimum cross-correlation values were reached in March, except w.r.t. TOPAZ4 reanalysis SIT in January.

The monthly L1 differences were smaller for the freeze-up period and increasing as the average ice thickness increased in the course of the winter as the average ice thickness increased. The L1 difference of the estimated SIT and remapped estimated SIT w.r.t. AARI SIT, and TOPAZ4 and ORAS5 reanalysis SIT were smaller for the remapped estimated SIT which was expected as the target of the remapping was to reduce the large positive bias. The average and maximum L1 difference w.r.t. AARI SIT were $48 / 78 \mathrm{~cm}$ for the estimated SIT and $36 \mathrm{~cm} / 48 \mathrm{~cm}$ for the remapped estimated SIT. The maximum values were reached in March and April. The corresponding values w.r.t. Topaz reanalysis were 48/77 cm and 38/52 cm and w.r.t ORAS5 SIT 46/63 $\mathrm{cm}$ and $37 / 45 \mathrm{~cm}$. The difference maxima were reached in April and March.

The biases (i.e. signed L1 differences) in Table III have been computed such that positive values indicate overestimation w.r.t. the reference value and negative values underestimation. The monthly bias (signed L1 differences) also increases for the estimated SIT w.r.t. both AARI SIT and TOPAZ4 renanalysis SIT as the ice gets thicker, indicating significant overestimation. For the remapped estimated SIT bias remain at a lower level for all the studied months, w.r.t. ORAS5 there was even small underestimation on average, but w.r.t. TOPAZ4 reanalysis SIT some overestimation. The averages and maximum biases for the estimated SIT w.r.t. AARI SIT were 32/67 cm (maximum reached in March). The corresponding values w.r.t. AARI SIT for the remapped estimated SIT were $21 / 41 \mathrm{~cm}$ (maximum underestimation in April). The corresponding values w.r.t. TOPAZ4 renanalysis SIT were $38 / 72 \mathrm{~cm}$ and $26 / 45 \mathrm{~cm}$, respectively. The corresponding values w.r.t. ORAS5 SIT were $-3 / 22 \mathrm{~cm}$ and $-15 /-22 \mathrm{~cm}$, i.e. slight underestimation. The biases of the remapped SIT w.r.t. ORAS5 SIT were slightly negative for all the months but still L1D and RMSD w.r.t. ORAS5 SIT were smaller for the remapped SIT than for the unmapped SIT.

The RMS difference has a similar behaviour as L1 differences. It also increases as the average ice thickness increases in the course of the winter and smallest RMSD values were reached during the freeze-up months (October-November). The average and monthly maximum RMSD values for the estimated SIT w.r.t. AARI SIT were were $64 / 94 \mathrm{~cm}$, and the corresponding values for the remapped estimated SIT were $45 / 57 \mathrm{~cm}$. The corresponding values w.r.t. TOPAZ4 reanalysis SIT were $69 / 98 \mathrm{~cm}$ for the estimated SIT and 51/64 cm for the remapped estimated SIT, and the corresponding values w.r.t. ORAS5 SIT were 60/80 for the estimated SIT and $48 / 59 \mathrm{~cm}$ for the estimated remapped SIT.

For the CS-2 SIT mapped to SAR segments, the difference measures shown in Tables I-IV, indicate large positive bias (overestimation) and other difference measures w.r.t. AARI SIT, TOPAZ4 and ORAS5 reanalysis SIT. These values are highest for the winter months with thickest ice and smaller for the freeze-up (October-November). The cross-correlations w.r.t. all reference data sets were low, significantly lower than for the estimated SIT. 
https://doi.org/10.5194/tc-2021-185

Preprint. Discussion started: 11 August 2021

(c) Author(s) 2021. CC BY 4.0 License.

\section{(c) $\underset{\mathrm{BY}}{\mathrm{BV}}$}

It should be noted that also the reference SIT data sets differ from each other. These differences are shown in Table V. The average cross-correlations between the reference data sets were in the range 0.54-0.60. TOPAZ4 and AARI SIT values were on average quite close to each other, having only low bias, ORAS5 SIT was then on average 35-40 cm above them.

Furthermore, the reader should note that in our evaluation the compared randomly sampled points were located in highly dissimilar regions, characteristic for the different data sets, with different sizes and shapes (such as ice model grid points, SAR segments, ice chart polygons).

In order to assess how far the SIT can be interpolated and still give usable estimates, we studied the effect of distance and time on the SIT difference (or in other words, estimation error) using our training data set of 2016. We used the assigned CS-2 SIT values as reference and searched for sets of segments with either constant time difference or constant distance and defined the increase of ice thickness difference as a function of the difference in the other.

The average increase in estimation error for the 2016 training data as a function of time was $1.6 \mathrm{~cm} / \mathrm{day}$ and of space was $1.3 \mathrm{~cm} / 100 \mathrm{~km}$. This indicates that the contribution of distance difference to the total difference is in maximum (corresponding to the search range boundaries) around $13 \mathrm{~cm}$ for the 1000 pixel spatial search range and $16 \mathrm{~cm}$ for the 10 day temporal search range. An example of the SIT estimation of 21 February 2017 without and with the remapping can be seen in Fig. 8. For reference also the AARI SIT and the TOPAZ4 and ORAS5 reanalysis SIT have been included in Fig. 8. This figure represents a typical case with a general agreement of the thinner and thicker ice fields generally in agreement compared to the reference data but still indicating quite much difference due to the details of the local SIT distribution, given in higher level of detail in the estimated CS2/SAR SIT.

As we are using a (segment) difference function, we compute its median value for each segment mapped. This value corresponds to the mapping and the larger it is the larger the uncertainty of the estimation can be considered. We have scaled the difference to the range 0-100 (based on the training data difference function values) and in Fig. 10 the scaled difference function for the estimation of 21 February 2017 is shown. The highest uncertainty is found at the ice edge and in the river $\mathrm{Ob}$ delta area. The uncertainly could probably also be used for iteratively re-estimating the SIT of segments with the highest uncertainties.

We also performed some comparisons of the CS-2/S-1 SIT estimates against the daily MODIS SIT charts. The MODIS product only gives thin ice thicknesses and the thicker ice thicknesses are very roughly categorized, i.e. one category for SIT of 31-50 cm and another for SIT over $50 \mathrm{~cm}$. There were MODIS SIT charts for the winter 2017 (January-April). The monthly correlations between the thin MODIS SIT $(1-30 \mathrm{~cm})$ and the SIT estimated by the proposed method varied between 0.15 to 0.25 . We also computed the averages of the estimated SIT for the three MODIS SIT categories, i.e. 1-30 cm, 31-50 cm and over $50 \mathrm{~cm}$ for each month and for the estimated SIT and estimated remapped SIT. These are presented in Table 5. It can be seen that the averages increase towards a thicker MODIS thickness category for both the estimates, but the increases are quite small and the averages are too high for both the methods, some less for the remapped estimate. It can also be seen that the averages increase as a function of time, i.e. as ice gets thicker in the course of time. Based on this experiment we can conclude that the estimates, even with the proposed remapping, tends to overestimate specifically thin ice thickness. For visual evaluation and comparison to the SIT estimates of Fig. 9 we also show the MODIS SIT collage for February 212017 in Fig. 10. The color 
https://doi.org/10.5194/tc-2021-185

Preprint. Discussion started: 11 August 2021

(c) Author(s) 2021. CC BY 4.0 License.

(c) (i)

scale is the same as in Fig. 9, except that the thickest MODIS SIT category (SIT $>50 \mathrm{~cm}$ ) is cyan in the figure. Because in a daily MODIS SIT chart SIT can typically be computed only for small areas due to cloud cover, the collage is composed of two weeks of MODIS SIT charts with the most recent available MODIS SIT value at each grid point. The areas with no data during the 2-week period are indicated by the black color in the figure.

When comparing the MODIS SIT collage of Fig. 10 with the daily CS-2/S-1 SIT estimate in Fig. 8b we notice that most of the ice-covered areas of the study area areas belong to the thickest MODIT SIT category (SIT $>50 \mathrm{~cm}$ ). The thin ice areas according to the MODIS SIT are located near the Kara gate (southern Kara Sea) and near the ice edge in the northwestern part of the study area. These are in general in agreement with the CS-2/S-1 SIT Also some thicker ice patches within or in the vicinity of the MODIS SIT thin ice areas can be identified in the CS-2/S-1 SIT. The general pattern detecting thinner ice in the south and near ice edge is present in both CS-2/S-1 and MODIS SIT. This general large scale pattern can be seen throughout the winter. However, the SIT estimates include many anomalous local details due to the dynamic nature of the ice field.

\section{Discussion and Conclusions}

In this study an algorithm for inter/extrapolating of the CS-2 SIT data over the S-1 daily SAR mosaic was developed and evaluated by comparisons to SIT derived from Russian Arctic AARI ice charts and two ice model reanalysis data sets. We wanted to demonstrate the potential of our method as well as to evaluate its performance. We found significant differences (both low correlation and high bias) between non-interpolated CS-2 SIT and the reference data. The match between CS2 and reference data improved with the introduction of segmentwise medians. However, there was still a significant difference, especially a high positive bias due to different nature of CS-2 estimates and the reference data sets. To reduce this bias, we performed a mapping based on the PDF's (histograms) of the CS-2 SIT and PIOMAS/ORAS5 model reanalysis SIT of the training data set. This mapping reduced the positive bias. However, the remapped CS-2 data should not be understood as more correct, but as one more akin to model SIT.

An interesting result was that the inter/extrapolation does not decrease the correlation compared to (incomplete) SIT resulting from CS-2 data assigned to SAR segments, or CS-2 data as individual measurements. In many cases correlations were even slightly higher for the results with the SAR data and inter/extrapolation included. Here the mapping was based on PIOMAS/ORAS5 model reanalysis data of the training data of 2016. TOPAZ4 reanalysis still seems to underestimate the high SIT values, this is suggested e.g. by the comparison results between TOPAZ4 and ORAS5 SIT in Table V.

In general, evaluation of ice thickness over Arctic is difficult because of lack of reliable reference data. Another problem is the scale of the SIT measurements, estimates and models. SIT measurements, if available, are typically point measurements or measurements with a footprint of a few meters to a few tens of meters (e.g. SIT measurements by drilling or Electromagnetic induction based EM measurents), and the model grid cells, EO measurements or segment-wise SAR estimates represent averages over several sqare kilometers $\left(\mathrm{km}^{2}\right)$. Also ice charts give averages of typically quite large polygons of several $\mathrm{km}^{2}$.

We selected parameters, such as N, empirically. The sensitivity of SIT to parameters chosen was not studied thoroughly yet. It will be a topic for future research. For example the value of $\mathrm{N}$ was selected such that we had enough segments with CS-2 SIT 
https://doi.org/10.5194/tc-2021-185

Preprint. Discussion started: 11 August 2021

(c) Author(s) 2021. CC BY 4.0 License.

(c) (i)

assigned to them to get inter/extrapolated SIT for all the segments of a daily SAR mosaic. Currently the value of N is relatively small for a typical SAR segment. A higher value of $\mathrm{N}$ would be preferable. However, a higher value of $\mathrm{N}$ in turn would reduce the number of segments included in the estimation and also increase the possibility of too few assigned SIT values for the inter/extrapolation step. For this reason we used a moderate value of $\mathrm{N}$.

The relatively larger differences w.r.t. the reference data sets can at least partly be explained by the different resolutions and level of detail of the SIT estimates. The CS-2/S-1 SIT has a resolution of $500 \mathrm{~m}$ (the SAR mosaic resolution) which is significantly higher than the resolution of the ORAS5, PIOMAS and TOPAZ4 reanalyses (over $10 \mathrm{~km}$ ) and also the ice chart level of detail. Furthermore the original CS-2 measurements stem from individual footprints that are approximately $300 \mathrm{~m}$ x $1600 \mathrm{~m}$. Even though the ice charts have a nominal resolution up to about $1 \mathrm{~km}$, in practice it is impossible for the ice analysts to include all the ice field details in this scale within the limited time available for making the ice charts. Instead, the ice analysts tend to draw larger polygons, representing rather homogeneous sea ice, neglecting the details, and assigning areal average values to the polygons. However, the polygon boundaries typically have the precision of the nominal ice chart resolution.

510 In the future we plan to study segment clustering and then assigning CS-2 SIT value median or mode of each segment cluster to all segments of a segment cluster instead of single segment medians. An easy solution would be to merge small segments into their neighboring larger segments to remove all the segments smaller than a given area. This would give more CS-2 measurements within the segments but on the other hand also giving SIT estimates representing averages of larger areas. Despite of this it should be noted that the segment boundaries, representing different ice fields, are still represented in the resolution of the segmentation. With these approaches we aim to overcome the problem of either having too few CS-2 SIT values assigned to segments or too few segments with an assigned SIT. Also more detailed utilization of SIT distributions of segment clusters with a large enough number of SIT samples for forming statistically reliable SIT distributions should be studied. Including thin ice detection (thickness $<20 \mathrm{~cm}$ ) from microwave radiometer using a method in (Makynen and Simila , 2019) could also improve the SIT estimation results. In some cases also large SAR segments could be split into smaller ones to get more detailed and more accurate local SIT estimates.

To match segments we compute the value of the segment-wise difference function $\mathrm{T}$ for the matched segments. The value of $\mathrm{T}$ could possibly be used to implement an iterative SIT assigning scheme. In this scheme only SIT values with $\mathrm{T}$ less than a selected threshold value would be assigned to segments and the process iterated using all the SIT values assigned during the previous iterations in assigning SIT values to the segments still without an assigned SIT at each iteration. The threshold to be applied could also be varying as a function of the iteration.

The evaluation of this study was performed for January-April and November-December. This was because both the CS-2 SIT and AARI ice chart ice stage of development were not available for wet surface conditions. For such conditions reliable estimation of SIT is difficult or even impossible with the current data and algorithms. This is due to the deviating behaviour of radar signal at the wet air/snow-ice boundary, compared to a frozen surface.

530 It may be possible to use the dependence of the biases on the phase of the winter (related to average SIT), such as early freeze-up, freeze-up, melt-donw phase, to reduce the bias by applying a bias-reducing mapping dependent on the phase of the 
https://doi.org/10.5194/tc-2021-185

Preprint. Discussion started: 11 August 2021

(c) Author(s) 2021. CC BY 4.0 License.

(c) (1)

winter instead on a common mapping for the whole winter. The phase of the winter could roughly be estimated based on the estimated average ice thickness.

We also studied use of regularized linear regression (LASSO) (Tibshiran , 1996) for reducing the number of texture features needed in the SIT estimation. According to our first tests the performance was nearly similar with less texture parameters involved, but on the other hand the need for computational resources with the amount of LS fit parameters used now were not significantly larger than with a reduced number of parameters, and thus we here used all the studied parameters in the LS fit in this study. In the future reduction of LS fit parameters could be studied more if necessary e.g. for more efficient computing to cover larger sea areas in a reasonable time. This may be required to meet conditions for operational production, e.g. for a 540 pan-Arctic high-resolution SIT product.

Our algorithm can be easily adapted to any satellite altimeter SIT product. It is especially relevant for the future CRISTAL mission (Kern et al., 2020). After its expected launch in late 2027, CRISTAL shall provide a time critical SIT product, which can be merged with SAR data to interpolate SIT between the CRISTAL ground tracks. Thus our study is one of the necessary steps in introducing satellite altimeter data into the realm of operational ice charting. Before CRISTAL, our algorithm can be applied to ICESat-2 as well as to Sentinel-3 based SIT estimates. 
https://doi.org/10.5194/tc-2021-185

Preprint. Discussion started: 11 August 2021

(c) Author(s) 2021. CC BY 4.0 License.

(c) (i)

\section{References}

[AARI] AARI ice chart web page, http://www.aari.ru/odata/_d0015.php?lang=1.

[1] Afanasyeva E.V., Alekseeva T.A., Sokolova J.V., Demchev D.M., Chufarova M.S., Bychenkov Yu.D., Devyataev O.S. / E.V. Afanasyeva, T.A. Alekseeva, J.V. Sokolova, D.M. Demchev, M.S. Chufarova, Yu.D. Bychenkov, O.S. Devyataev, AARI methodology for sea ice charts composition, Russian Arctic, n. 7. pp. 5-20, 2019.

[2] Armitage, T. W. K. and Ridout, A. L., Arctic sea ice freeboard from AltiKa and comparison with CryoSat-2 and Operation IceBridge, Geophys. Res. Lett., 42, 6724-6731, https://doi.org/10.1002/2015GL064823, 2015.

[3] Besag, J., On the Statistical Analysis of Dirty Pictures, J. R. Statis. Soc. B, v. 48, n. 3, pp. 259-302, 1986

[4] Bourbigot, M., H. Johnsen, R. Piantanida, SENTINEL-1 ProductSpecification, document S1-RS-MDA-52-7441, ESA, 2016.

[5] Box, G. E. P., and Jenkins, G., Time Series Analysis: Forecasting and Control, Holden-Day, 1976.

[6] Bushuev, A.V.; Loshchilov, V.S. Ice chart composition at AARI. In Remote sensing of sea ice in the northern sea route: studies and applications; Johannessen, O.M; Alexandrov, V.Y.; Frolov, I.Y; Sandven, S.; Pettersson, L.H.; Bobylev, L.P.; Kloster, K.; Smirnov, V.G.; Mironov, Y.U.; Babich, N.G; Springer-Praxis: Chichester, UK, Volume 3, pp. 243-252, 2007.

[7] Cressie, N., Statistics for spatial data, pp. 69-101, Wiley, New York, 1993.

[8] Evensen, G., Sequential data assimilation with a nonlinear quasi-geostrophic model using Monte-Carlo methods to forecast errorstatistics, J. Geophys. Res., v. 99, n. 10, pp. 143-10 162, 1994.

[9] Frey R. A,, et al., Cloud detection with MODIS. Part I: Improvements in the MODIS cloud mask for collection 5, J. Atmos. Ocean. Technol., vol. 25, no. 7, pp. 1057-1072, 2008.

[10] Fukunaga, K., L. D. Hostetler, The Estimation of the Gradient of a Density Function, with Applications in Pattern Recognition. IEEE Transactions on Information Theory. v. 21, n. 1, pp. 32-40, 1975.

[11] Giles, K. A., et al., Circumpolar thinning of Arctic sea ice following the 2007 record ice extent minimum, Geophys Res Lett, 35(22), doi:10.1029/2008GL035710, 2008.

[12] Hackett, B., L. Bertino, A. Ali, A. Burud, T. Williams Product User Manual for Arctic Ocean Physical and Bio Analysis and Forecasting Products, issue 5.10, https://resources.marine.copernicus.eu/documents/PUM/CMEMS-ARC-PUM-002-ALL.pdf, 2020.

[13] S. Hendricks, R. Ricker, V. Helm, AWI CryoSat-2 Sea Ice Thickness Data Product (v1.2), Alfred Wegener Institute (AWI), Bremerhafen, 2016.

[14] Huntemann, M., G. Heygster, L. Kaleschke, T. Krumpen, M. Makynen, and M. Drusch, Empirical sea ice thickness retrieval during the freezeup period from SMOS high incident angle observations, Cryosphere, vol. 8, no. 2, pp. 439-451, 2014.

[15] Iwamoto, K., K. I. Ohshima, T. Tamura, Improved mapping of sea ice production in the Arctic Ocean using AMSR-E thin ice thickness algorithm, J. Geophys. Res., vol. 119, no. 6, pp. 3574-3594, Jun. 2014.

[16] JCOMM Expert Team on Sea Ice, Sea-ice nomenclature: Snapshot of the WMO sea ice nomenclature WMO no. 259, World Meteorological Organization, Geneva, Switzerland, Tech. Rep., 2014.

[17] JCOMM Expert Team on Sea Ice. SIGRID-3: a vector archive format for sea ice georeferenced information and data, JCOMM Technical Report No. 23, World Meteorological Organization, Geneva, Switzerland, 2014.

[18] 49. Johannessen, O.M; Alexandrov, V.Y.; Frolov, I.Y; Sandven, S.; Pettersson, L.H., Bobylev, L.P., Kloster, K.; Smirnov, V.G., Mironov, Y.U.;, Babich, N.G., Remote sensing of sea ice in the northern sea route: studies and applications, Springer-Praxis: Chichester, UK, pp. 25-64, 2007. 
https://doi.org/10.5194/tc-2021-185

Preprint. Discussion started: 11 August 2021

(c) Author(s) 2021. CC BY 4.0 License.

(c) (i)

[19] Kaleschke, L., X. Tian-Kunze, N. Maaß, M. Makynen, M. Drusch, Sea ice thickness retrieval from SMOS brightness temperatures during the Arctic freeze-up period, Geophys. Res. Lett., vol. 39, no. 5, p. L05501, 2012.

[20] Kaleschke L., et al., SMOS sea ice product: Operational application and validation in the Barents Sea marginal ice zone, Remote Sens. Environ., vol. 180, pp. 264-273, Jan. 2016.

[21] Kalnay, E., M. Kanamitsu, R. Kistler, W. Collins, D. Deaven, L. Gandin, M. Iredell, S. Saha, G. White, J. Woollen, Y. Zhu, A. Leetmaa, R. Reynolds, M. Chelliah, W. Ebisuzaki, W.Higgins, J. Janowiak, K. C. Mo, C. Ropelewski, J. Wang, R. Jenne, D. Joseph, The NCEP/NCAR 40-year reanalysis project, Bulletin of the American Meteorological Society, v. 77, pp. 437-470, 1996.

[24] Karvonen, J., Virtual radar ice buoys — A method for measuring fine-scale sea ice drift, Cryosphere, vol. 10, pp. 29—42, ,doi: $10.5194 /$ tc-10-29-2016, 2016

[23] Karvonen, J., Baltic Sea Ice Concentration Estimation Using SENTINEL-1 SAR and AMSR2 Microwave Radiometer Data, IEEE Transactions on Geoscience and Remote Sensing, v. 55 , n. 5, pp, 2871-2883, 2017

[24] J. Karvonen, Virtual radar ice buoys - a method for measuring fine-scale sea ice drift, The Cryosphere, 10, 29-42, 2016.

[25] Kern, S., K. Khvorostovsky, H. Skourup, E. Rinne, Z. S. Parsakhoo, V. Djepa, P. Wadhams, S. Sandven, The impact of snow depth, snow density and ice density on sea ice thickness retrieval from satellite radar altimetry: results from the ESA-CCI Sea Ice ECV Project Round Robin Exercise, The Cryosphere, 9, 37-52, 2015, https://doi.org/10.5194/tc-9-37-2015.

[26] Kern, M., R. Cullen, B. Berruti, J. Bouffard, T. Casal, M. R. Drinkwater, A. Gabriele, A. Lecuyot, M. Ludwig, R. Midthassel, I. N. Traver, T. Parrinello, G. Ressler, E. Andersson, C. Martin-Puig, O. Andersen, A. Bartsch, S. Farrell, S. Fleury, S. Gascoin, A. Guillot, The Copernicus Polar Ice and Snow Topography Altimeter (CRISTAL) high-priority candidate mission, The Cryosphere, 14, 2235-2251, 2020. https://doi.org/10.5194/tc-14-2235-2020

[27] Knapp, C. H. and G.C. Carter, The Generalized Correlation Method for Estimation of Time Delay, IEEE Transactions on Acoustics, Speech and Signal Processing, v. ASSP-24, n. 4, pp. 320-327, 1976.

[28] Kurtz, N. T. and Farrell, S. L., Large-scale surveys of snow depth on Arctic sea ice from operation IceBridge, Geophys. Res. Lett., 38, L20505, DOI: 10.1029/2011GL049216, 2011.

[29] Kurtz, N. T., N. Galin, M. Studinger, An improved CryoSat-2 sea ice freeboard retrieval algorithm through the use of waveform fitting, The Cryosphere, 8, 1217-1237, DOI: 10.5194/tc-8-1217-2014, 2014.

[30] Kwok R., Nghiem S. V., Yueh S. H., Huynh D. D., Retrieval of thin ice thickness from multifrequency polarimetric SAR data. Remote Sens. Environ., 51(3), 361-374, 1995.

610 [31] Kwok, R., G. F. Cunningham, ICESat over Arctic sea ice: Estimation of snow depth and ice thickness, J. Geophys. Res.-Oceans, 113, c08010, https://doi.org/10.1029/2008JC004753, 2008.

[32] Kwok et al., Thinning and volume loss of the Arctic Ocean sea ice cover: 2003-2008, J. Geophys. Res.-Oceans, 114, DOI: 10.1029/2009JC005312, 2009.

[33] Laxon, S., N. Peacock, D. Smith, High interannual variability of sea ice thickness in the Arctic region, Nature, 425, 947-950, 2003

615 [34] Laxon, S. W., K. A. Giles, A. L. Ridout, D. J. Wingham, R. Willatt, R. Cullen, R. Kwok, A. Schweiger, J. Zhang, C. Haas, S. Hendricks, R. Krishfield, N. Kurtz, S. Farrell, M. Davidson CryoSat-2 estimates of Arctic sea ice thickness and volume, Geophysical Research Letters v. 40, pp. 732-737, 2013.

[35] Lemieux, Jean-François, Sylvain Bouillon, Frédéric Dupont, Gregory Flato, Martin Losch, Pierre Rampal, Louis-Bruno Tremblay, Martin Vancoppenolle, and Timothy Williams. 'Sea Ice Physics and Modelling'. In Sea Ice Analysis and Forecasting. Cambridge University Press, doi:10.1017/9781108277600.003, 2018. 
https://doi.org/10.5194/tc-2021-185

Preprint. Discussion started: 11 August 2021

(c) Author(s) 2021. CC BY 4.0 License.

(c) (i)

[36] Mäkynen, M., B. Cheng, M. Similä, On the accuracy of thin-ice thickness retrieval using MODIS thermal imagery over Arctic first-year ice, Ann. Glaciol., vol. 54, no. 62, pp. 87-96, 2013.

[37] Makynen, M., J. Karvonen, MODIS sea ice thickness and open water-sea ice charts over the Barents and Kara Seas for development and validation of sea ice products from microwave sensor data, Remote Sens., vol. 9, no. 12, p. 1324, 2017.

[38] Makynen, M., J. Karvonen, Incidence Angle Dependence of First-Year Sea Ice Backscattering Coefficient in Sentinel-1 SAR Imagery Over the Kara Sea, IEEE Transactions on Geoscience and Remote Sensing, v. 55, n. 11, pp 6170-6181, 2017.

[39] Makynen, M., M. Simila, Thin ice detection in the Barents and Kara Seas using AMSR2 high-frequency radiometer data, IEEE Trans. on Geoscience and Remote Sensing, vol. 57, no. 10, pp. 7418-7437, 2019.

[40] Martin, S., R. Drucker, R. Kwok, B. Holt, Estimation of the thin ice thickness and heat flux for the Chukchi Sea Alaskan coast polynya from Special Sensor Microwave/Imager data, 1990-2001, J. Geophys. Res. Oceans, vol. 109, no. C10, p. C10012, 2004.

[41] Nakamura K, Wakabayashi H, Uto S, Naoki K, Nishio F., Uratsuka S., Sea-ice thickness retrieval in the Sea of Okhotsk using dualpolarization SAR data. Ann. Glaciol., 44, 261-268, 2006.

[42] Nakata, K., K. I. Ohshima, S. Nihashi, Estimation of thin-ice thickness and discrimination of ice type from AMSR-E passive microwave data, IEEE Trans. Geosci. Remote Sens., vol. 57, no. 1, pp. 263-276, Aug. 2019.

635 [43] T. Ojala, M. Pietikäinen, D. Harwood, A comparative study of texture measures with classification based on featured distributions, Pattern Recognit., vol. 29, no. 1, pp. 51-59, 1996.

[44] Ohshima, K. I., S. Nihashi, K. Iwamoto, Global view of sea-ice production in polynyas and its linkage to dense/bottom water formation, Geosci. Lett., vol. 3, no. 1, p. 13, 2016.

[45] Petty, A.A., Kurtz, N.T., Kwok, R., Markus, T., Neumann, T.A, Winter arctic sea ice thickness from ICESat-2 freeboards. Journal of Geophysical Research: Oceans, 125, e2019JC015764, https://doi.org/10.1029/2019JC015764, 2020.

[46] Paul, S., S. Willmes, and G. Heinemann, Long-term coastal-polynya dynamics in the southern Weddell sea from MODIS thermalinfrared imagery, Cryosphere, vol. 9, no. 6, pp. 2027-2041, Nov. 2015.

[47] Ricker, R., S. Hendricks, V. Helm, H. Skourup, M. Davidson, Sensitivity of CryoSat-2 Arctic sea-ice freeboard and thickness on radar-waveform interpretation, The Cryosphere, v. 8 n. 4, pp. 1607-1622, doi:10.5194/tc-8-1607-2014, 2014.

[48] Ricker R., S. Hendricks, L. Kaleschke, X. Tian-Kunze, J. King, C. Haas, A weekly Arctic sea-ice thickness data record from merged CryoSat-2 and SMOS satellite data , The Cryosphere, 11, 1607-1623, https://doi.org/10.5194/tc-11-1607-2017, 2017.

[49] Sakov P., F. Counillon, L. Bertino1, K. A. Lisæter, P. R. Oke, A. Korablev, TOPAZ4: an ocean-sea ice data assimilation system for the North Atlantic and Arctic, Ocean Science, v. 8, pp. 633-656, https://doi.org/10.5194/os-8-633-2012, 2012.

[50] S. Sandven, O.M. Johannesen, Sea Ice Monitoring by Remote Sensing, Manual of Remote Sensing: Remote Sensing of the Marine Environment, James F.R. Gower, 3rd Edition, v. 6, pp. 241-283, Bethesda: American Society for Photogrammetry \& Remote Sensing, 2006.

[51] A. Schmitt and L. Kaleschke, "A consistent combination of brightness temperatures from SMOS and SMAP over Polar Oceans for sea ice applications," Remote Sens., vol. 10, no. 4, p. 553, doi: 10.3390/rs10040553, 2018.

[52] Schweiger, A., R. Lindsay, J. Zhang, M. Steele, H. Stern, and R. Kwok, Uncertainty in modeled Arctic sea ice volume, J. Geophys. Res., 116, C00D06, doi:10.1029/2011JC007084, 2011.

[53] C. E. Shannon, A Mathematical Theory of Communication, The Bell System Technical Journal, v. 27, pp. 379-423, 623-656, 1948.

[54] Simila M., Makynen M., Heiler I., Comparison between C band synthetic aperture radar and 3-D laser scanner statistics for the Baltic Sea ice. J. Geophys. Res., 115(C10), C10056, 2010. 
https://doi.org/10.5194/tc-2021-185

Preprint. Discussion started: 11 August 2021

(c) Author(s) 2021. CC BY 4.0 License.

(c) (i)

[55] Simila M., M. Makynen, J. Karvonen, A. Gegiuc, A. Gierisch, Modeled Sea Ice Thickness Enhanced by Remote Sensing Data, Proc. ESA Living Planet Symposium 2016, Prague, Czech Republic, May 2016.

[56] Tian-Kunze, X., et al., SMOS-derived thin sea ice thickness: Algorithm baseline, product specifications and initial verification, Cryosphere, vol. 8, no. 3, pp. 997-1018, 2014.

[57] Tibshirani, R., Regression Shrinkage and Selection via the lasso, Journal of the Royal Statistical Society. Series B (methodological). Wiley. v. 58 n. 1, pp. 267-288, 1996.

665 [58] Tietsche, S., M. A. Balmaseda, H. Zuo, K. Mogensen, Arctic sea ice in the global eddy-permitting ocean reanalysis ORAP5, Clim. Dyn., v. 49, pp. 775-789, DOI 10.1007/s00382-015-2673-3, 2017.

[59] Tilling, R. L., Ridout, A., Shepherd, A., Wingham, D. J., Increased Arctic sea ice volume after anomalously low melting in 2013, Nat. Geosci., 8, 643-646, 2015.

[60] Tilling, R. L., A. Ridout, A. Shepherd, Estimating Arctic sea ice thickness and volume using CryoSat-2 radar altimeter data, Adv. Space Res., 62, 1203-1225, 2018.

[61] Toyota, T., Ono, S., Cho, K., Ohshima, K.. Retrieval of sea-ice thickness distribution in the Sea of Okhotsk from ALOS/PALSAR backscatter data. Annals of Glaciology, 52(57), 177-184, 2011.

[62] Wadhams, P., Aulicino, G., Parmiggiani, F., Persson, P.O.G., Holt, B., Pancake ice thickness mapping in the Beaufort Sea From wave dispersion observed in SAR imagery. J. Geophys. Res. Oceans, 123, 2213-2237, 2018.

675 [63] Wakabayashi H., Matsuoka T., Nakamura K., Nishio F., Polarimetric characteristics of sea ice in the Sea of Okhotsk observed by airborne L-band SAR. IEEE Trans. Geosci. Remote Sens., 42(11), 2412-2425, 2004.

[64] Warren, S. G., I. G. Rigor, N. Untersteiner, V. F. Radionov, N. N. Bryazgin, Y. I. Aleksandrov, R. Colony, Snow Depth on Arctic Sea Ice, J. Climate, 12, 1814-1829, https://doi.org/10.1175/1520-0442(1999)012<1814:SDOASI>2.0.CO;2, 1999.

[65] Wessel P., W. H. F. Smith, A Global Self-consistent, Hierarchical, High-resolution Shoreline Database, Journal of Geophysical Research, v. 101, n. B4, pp. 8741-8743, DOI: 10.1029/96JB00104, 1996.

[66] WMO, WMO Sea-Ice Nomenclature, World Meteorological Organization, Report No.259, available online: http://www.jcomm.info/index.php?option=com_oe\&task=viewDocumentRecord\&docID=14598, 2015.

[67] Wingham, D., C. Francis, S. Baker, C. Bouzinac, D. Brockley, R. Cullen, P. de Chateau-Thierry, S. Laxon, U. Mallow, C. Mavrocordatos, L. Phalippou, G. Ratier, L. Rey, F. Rostan, P. Viau, D. Wallis, CryoSat: A mission to determine the fluctuations in Earth's land and marine ice fields, Adv. Space Res., 37, 841-871, https://doi.org/10.1016/j.asr.2005.07.027, 2006.

[WMO] WMO egg code description:

http://www.natice.noaa.gov/products/egg_code.html

[68] Xia, W. and Xie, H., Assessing three waveform retrackers on sea ice freeboard retrieval from Cryosat-2 using Operation IceBridge Airborne altimetry datasets, Remote Sens. Environ., 204, 450-471, https://doi.org/10.1016/j.rse.2017.10.010, 2018.

[69] Xie, J., Counillon, F., and Bertino, L.: Impact of assimilating a merged sea-ice thickness from CryoSat-2 and SMOS in the Arctic reanalysis, The Cryosphere, 12, 3671-3691, https://doi.org/10.5194/tc-12-3671-2018, 2018.

[70] Xu, S., Zhou, L., and Wang, B., Variability scaling and consistency in airborne and satellite altimetry measurements of Arctic sea ice, The Cryosphere, 14, 751-767, https://doi.org/10.5194/tc-14-751-2020, 2020.

[71] Yi, D., N. Kurtz, J. Harbeck, R. Kwok, S. Hendricks, R. Ricker, Comparing Coincident Elevation and Freeboard From IceBridge and Five Different CryoSat-2 Retrackers, IEEE T. Geosci. Remote, 57, 1219-1229, https://doi.org/10.1109/TGRS.2018.2865257, 2018.

[72] Yu Y., D. A. Rothrock, Thin ice thickness from satellite thermal imagery, J. Geophys. Res., vol. 101, no. C11, pp. 25753-25766, 1996. 
https://doi.org/10.5194/tc-2021-185

Preprint. Discussion started: 11 August 2021

(C) Author(s) 2021. CC BY 4.0 License.

(c) (1)

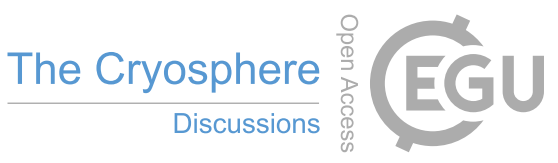

[73] Zhang, J.L. and D.A. Rothrock, Modeling global sea ice with a thickness and enthalpy distribution model in generalized curvilinear coordinates, Mon. Weather Rev., 131, 845-861, 2003.

[74] Zhang, X., Dierking, W., Zhang, J., Meng, J., and Lang, H.: Retrieval of the thickness of undeformed sea ice from simulated C-band compact polarimetric SAR images, The Cryosphere, 10, 1529-1545, https://doi.org/10.5194/tc-10-1529-2016, 2016.

[75] Zuo, H., Balmaseda, M. A., de Boisseson, E., Hirahara, S., Chrust, M., and De Rosnay, P., A generic ensemble generation scheme for data assimilation and ocean analysis, ECMWF Tech Memo., https://doi.org/10.21957/cub7mq0i4, 2017.

[76] Zuo, H., Balmaseda, M. A., Tietsche, S., Mogensen, K., and Mayer, M., The ECMWF operational ensemble reanalysis-analysis system for ocean and sea ice: a description of the system and assessment, Ocean Sci., 15, 779-808, https://doi.org/10.5194/os-15-779-2019, 2019.

705 [77] Zygmuntowska, M., P. Rampal, N. Ivanova, L. H. Smedsrud, Uncertainties in Arctic sea ice thickness and volume: new estimates and implications for trends, The Cryosphere, 8, 705-720, https://doi.org/10.5194/tc-8-705-2014, 2014. 
Table 1. Monthly average cross-correlations between the SIT estimates studied w.r.t. to the reference data set SIT. SIT refers to the proposed algorithm SIT, RSIT referes to the proposed algorithm SIT with remapping based on the histogram mapping with model data, CS2 refers to the CS-2 values assigned to the SAR segments (without inter- or extrapolation), A refers to the SIT derived from AARI ice charts, T refers to the Topaz4 model reanalysis SIT, and O refers to the ORAS5 model SIT.

\begin{tabular}{|c||c|c|c|c|c|c|c|c|c|}
\hline Month & CS2/A & SIT/A & RSIT/A & CS2/T & SIT/T & RSIT/T & CS2/O & SIT/O & RSIT/O \\
\hline $01 / 17$ & 0.05 & 0.26 & 0.30 & 0.05 & 0.19 & 0.25 & -0.03 & 0.28 & 0.35 \\
$02 / 17$ & 0.43 & 0.29 & 0.31 & 0.33 & 0.27 & 0.30 & 0.26 & 0.32 & 0.35 \\
$03 / 17$ & 0.21 & 0.24 & 0.25 & 0.12 & 0.34 & 0.38 & 0.07 & 0.23 & 0.26 \\
$04 / 17$ & 0.24 & 0.38 & 0.41 & 0.28 & 0.41 & 0.40 & 0.09 & 0.34 & 0.38 \\
$10 / 17$ & 0.34 & 0.73 & 0.73 & 0.29 & 0.71 & 0.73 & 0.25 & 0.63 & 0.66 \\
$11 / 17$ & 0.37 & 0.44 & 0.45 & 0.27 & 0.45 & 0.51 & 0.25 & 0.35 & 0.40 \\
$12 / 17$ & -0.07 & 0.28 & 0.31 & -0.06 & 0.34 & 0.40 & -0.05 & 0.29 & 0.33 \\
\hline Ave. & 0.22 & 0.37 & 0.39 & 0.18 & 0.39 & 0.42 & 0.12 & 0.35 & 0.39 \\
Std. & 0.18 & 0.17 & 0.16 & 0.15 & 0.16 & 0.16 & 0.14 & 0.13 & 0.13 \\
\hline
\end{tabular}

Table 2. Monthly average bias between the different SIT estimates w.r.t. the refererence data sets SIT. The symbols are the same as in Table 1.

\begin{tabular}{|c||c|c|c|c|c|c|c|c|c|}
\hline Month & CS2/A & SIT/A & RSIT/A & CS2/T & SIT/T & RSIT/T & CS2/O & SIT/O & RSIT/O \\
\hline $01 / 17$ & 41.5 & 26.5 & 25.1 & 36.0 & 30.7 & 29.3 & -9.6 & -19.3 & -20.8 \\
$02 / 17$ & 43.1 & 57.5 & 41.4 & 35.4 & 61.2 & 45.0 & -1.4 & 12.3 & -3.8 \\
$03 / 17$ & 54.1 & 66.8 & 35.4 & 47.8 & 72.4 & 41.0 & 14.5 & 28.6 & -2.9 \\
$04 / 17$ & 47.4 & 58.0 & 24.3 & 42.2 & 66.5 & 32.8 & 5.7 & 18.6 & -15.1 \\
$10 / 17$ & -1.4 & 5.0 & -0.5 & -5.3 & 8.7 & 3.2 & -18.2 & -16.8 & -22.4 \\
$11 / 17$ & 13.3 & 15.4 & 17.3 & 8.2 & 17.6 & 19.5 & -20.5 & -18.5 & -16.6 \\
$12 / 17$ & 19.8 & 17.2 & 22.0 & 11.9 & 17.0 & 21.8 & -21.6 & -22.8 & -18.0 \\
\hline Ave. & 34.6 & 32.5 & 20.7 & 31.1 & 37.6 & 25.8 & -0.1 & -3.2 & -15.0 \\
Std. & 20.6 & 24.9 & 13.4 & 20.1 & 26.7 & 14.2 & 14.0 & 21.6 & 7.8 \\
\hline
\end{tabular}


https://doi.org/10.5194/tc-2021-185

Preprint. Discussion started: 11 August 2021

(c) Author(s) 2021. CC BY 4.0 License.

Table 3. Monthly average L1 difference between the different SIT estimates w.r.t. the refererence data sets SIT. The symbols are the same as in Table 1.

\begin{tabular}{|c||c|c|c|c|c|c|c|c|c|}
\hline Month & CS2/A & SIT/A & RSIT/A & CS2/T & SIT/T & RSIT/T & CS2/O & SIT/O & RSIT/O \\
\hline $01 / 17$ & 52.0 & 40.8 & 38.3 & 52.5 & 43.2 & 41.0 & 49.2 & 43.2 & 38.8 \\
$02 / 17$ & 52.2 & 64.2 & 48.1 & 49.8 & 66.9 & 52.1 & 43.3 & 47.1 & 38.3 \\
$03 / 17$ & 68.5 & 78.4 & 47.6 & 67.2 & 77.2 & 49.4 & 60.7 & 62.8 & 44.8 \\
$04 / 17$ & 62.0 & 69.7 & 38.0 & 63.8 & 75.8 & 50.6 & 56.3 & 57.9 & 45.3 \\
$10 / 17$ & 33.5 & 28.1 & 22.5 & 40.8 & 26.1 & 22.4 & 36.7 & 38.7 & 33.5 \\
$11 / 17$ & 24.8 & 29.3 & 30.4 & 27.7 & 27.5 & 27.9 & 30.5 & 35.3 & 30.4 \\
$12 / 17$ & 30.5 & 28.2 & 32.0 & 29.5 & 26.7 & 29.0 & 35.6 & 32.5 & 27.6 \\
\hline Ave. & 50.2 & 48.0 & 36.3 & 53.1 & 48.1 & 37.9 & 48.6 & 45.6 & 37.0 \\
Std. & 16.7 & 21.8 & 9.3 & 15.5 & 23.6 & 12.4 & 11.2 & 11.4 & 6.8 \\
\hline
\end{tabular}

Table 4. Monthly average RMS difference between the different SIT estimates w.r.t. the refererence data sets SIT. The symbols are the same as in Table 1.

\begin{tabular}{|c||c|c|c|c|c|c|c|c|c|}
\hline Month & CS2/A & SIT/A & RSIT/A & CS2/T & SIT/T & RSIT/T & CS2/O & SIT/O & RSIT/O \\
\hline $01 / 17$ & 69.7 & 54.3 & 46.3 & 70.8 & 59.5 & 51.6 & 66.1 & 55.6 & 48.8 \\
$02 / 17$ & 67.6 & 79.2 & 56.2 & 67.4 & 84.4 & 62.9 & 61.9 & 62.3 & 49.5 \\
$03 / 17$ & 83.9 & 93.9 & 57.1 & 87.1 & 98.0 & 63.0 & 79.1 & 80.4 & 58.7 \\
$04 / 17$ & 72.6 & 84.6 & 48.2 & 78.7 & 94.2 & 63.6 & 72.5 & 73.5 & 58.5 \\
$10 / 17$ & 42.1 & 39.5 & 31.5 & 50.0 & 41.3 & 33.6 & 45.8 & 47.2 & 41.0 \\
$11 / 17$ & 33.3 & 40.4 & 37.2 & 36.4 & 41.6 & 37.9 & 37.6 & 43.6 & 38.3 \\
$12 / 17$ & 47.2 & 35.6 & 36.8 & 47.3 & 37.2 & 37.8 & 48.6 & 41.1 & 37.0 \\
\hline Ave. & 65.3 & 64.3 & 45.5 & 71.3 & 68.7 & 50.7 & 64.7 & 59.5 & 48.2 \\
Std. & 18.6 & 24.3 & 10.0 & 18.4 & 26.6 & 13.5 & 15.2 & 15.1 & 9.1 \\
\hline
\end{tabular}

Table 5. Monthly average difference measures between the reference data sets. The symbols are the same as in Table 1 .

\begin{tabular}{|c||c|c|c|c|c|c|c|c|c|c|c|c|}
\hline \multicolumn{1}{|c||}{ Month } & \multicolumn{3}{c|}{ CC } & \multicolumn{3}{c|}{ Bias } & \multicolumn{3}{c|}{ L1D } & \multicolumn{3}{c|}{ RMSD } \\
& T/A & O/A & O/T & T/A & O/A & O/T & T/A & O/A & O/T & T/A & O/A & O/T \\
\hline $01 / 17$ & 0.32 & 0.47 & 0.48 & -4.2 & 45.9 & 50.1 & 20.2 & 50.9 & 51.7 & 32.2 & 57.4 & 61.4 \\
$02 / 17$ & 0.43 & 0.54 & 0.51 & -3.6 & 45.2 & 48.9 & 23.4 & 49.8 & 50.5 & 36.0 & 60.9 & 65.6 \\
$03 / 17$ & 0.43 & 0.49 & 0.48 & -5.6 & 38.2 & 43.9 & 29.1 & 46.2 & 48.8 & 42.6 & 60.7 & 67.3 \\
$04 / 17$ & 0.51 & 0.49 & 0.46 & -8.5 & 39.4 & 47.9 & 33.1 & 48.0 & 57.4 & 48.5 & 63.7 & 75.2 \\
$10 / 17$ & 0.86 & 0.71 & 0.78 & -3.7 & 21.8 & 25.5 & 17.2 & 30.5 & 32.7 & 24.3 & 35.3 & 38.7 \\
$11 / 17$ & 0.69 & 0.46 & 0.62 & -2.2 & 33.9 & 36.1 & 13.1 & 37.4 & 37.3 & 18.8 & 39.9 & 41.7 \\
$12 / 17$ & 0.48 & 0.40 & 0.51 & 0.2 & 40.1 & 39.8 & 16.1 & 43.7 & 40.8 & 23.1 & 46.8 & 47.4 \\
\hline Ave. & 0.60 & 0.54 & 0.56 & -5.1 & 35.7 & 40.9 & 22.3 & 43.0 & 44.9 & 34.4 & 52.4 & 57.5 \\
\hline
\end{tabular}


https://doi.org/10.5194/tc-2021-185

Preprint. Discussion started: 11 August 2021

(c) Author(s) 2021. CC BY 4.0 License.

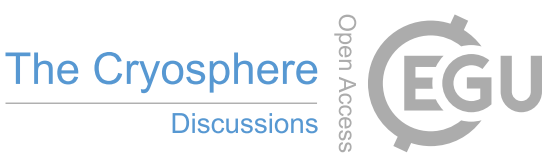
(c) (i)

Table 6. Monthly averages averages of estimated SIT (SIT) and remapped SIT (Rem. SIT) for the MODIS SIT categories. The MODIS SIT categories are 1-30 cm (Cat1), 31-50 cm (Cat2) and over $50 \mathrm{~cm}$ (Cat3).

\begin{tabular}{|c||c|c|c||c|c|c|}
\hline Month & SIT ave. Cat1 & SIT ave. Cat2 & SIT ave. Cat3 & Rem. SIT ave. Cat1 & Rem. SIT ave. Cat2 & Rem. SIT Cat3 \\
\hline \hline $01 / 2017$ & 61 & 71 & 73 & 59 & 69 & 70 \\
$02 / 2017$ & 97 & 112 & 115 & 80 & 91 & 94 \\
$03 / 2017$ & 135 & 142 & 145 & 100 & 106 & 108 \\
$04 / 2017$ & 140 & 146 & 151 & 102 & 106 & 109 \\
\hline
\end{tabular}



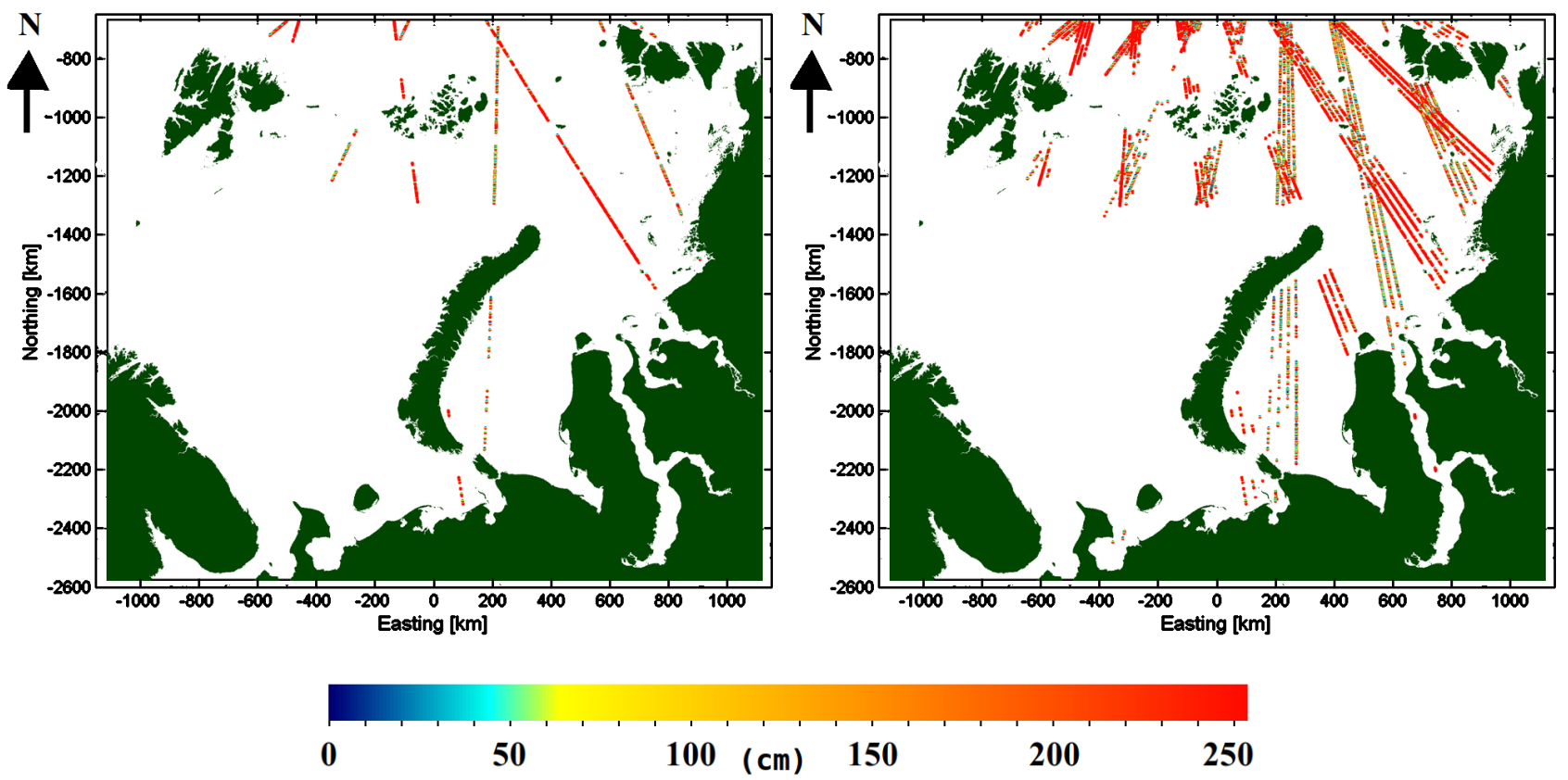

Figure 1. CS-2 SIT measurements of 1 day and one week before $21 \mathrm{Feb} 2017$. The colormap ends up to $250 \mathrm{~cm}$, ice thicker than $250 \mathrm{~cm}$ appears as red. 
https://doi.org/10.5194/tc-2021-185

Preprint. Discussion started: 11 August 2021

(c) Author(s) 2021. CC BY 4.0 License.

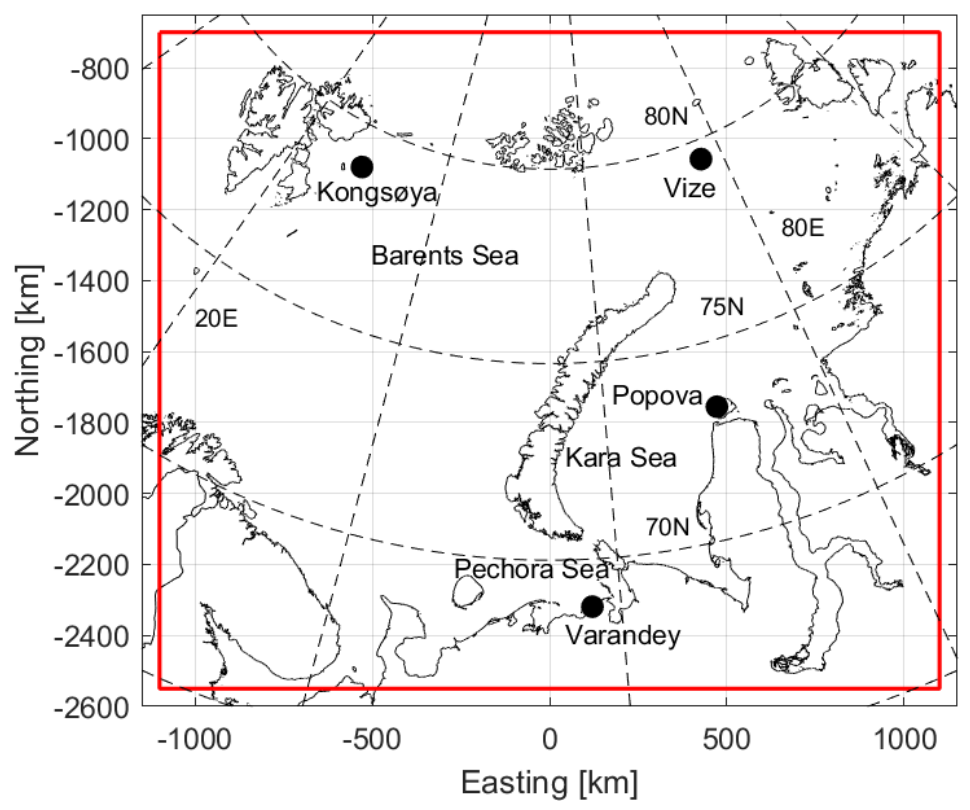

Figure 2. The study area in the used polar stereographic projection.
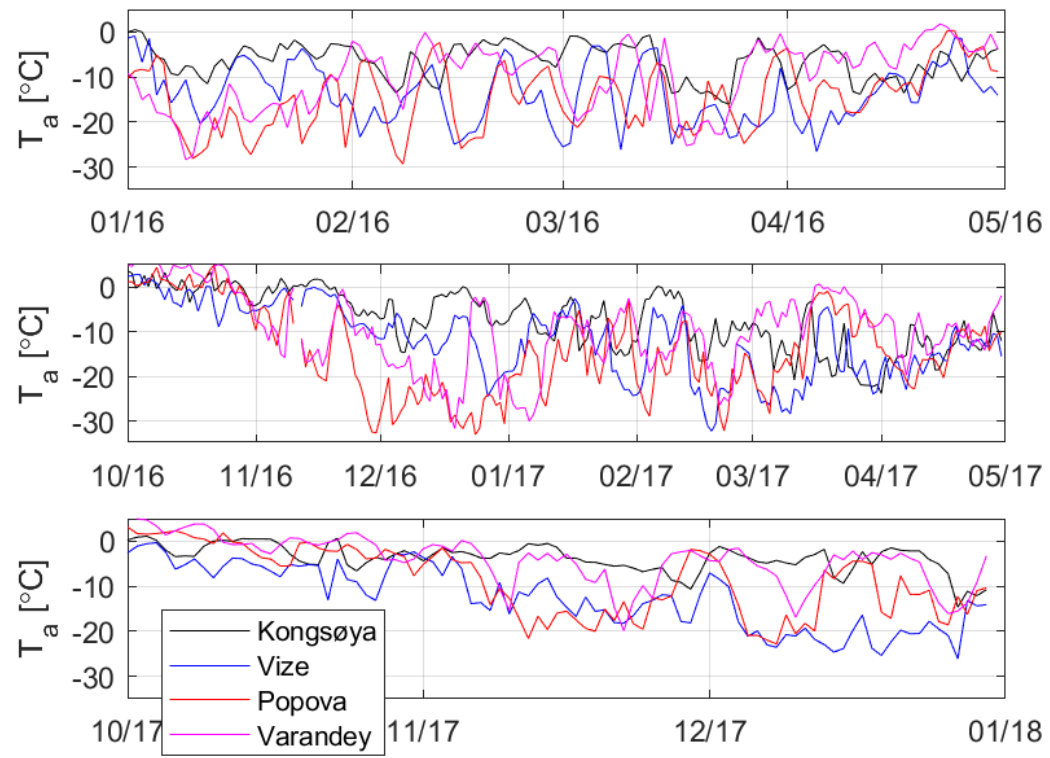

Figure 3. NCEP/NCAR reanalysis average daily air temperature during the period 2016-2017. 

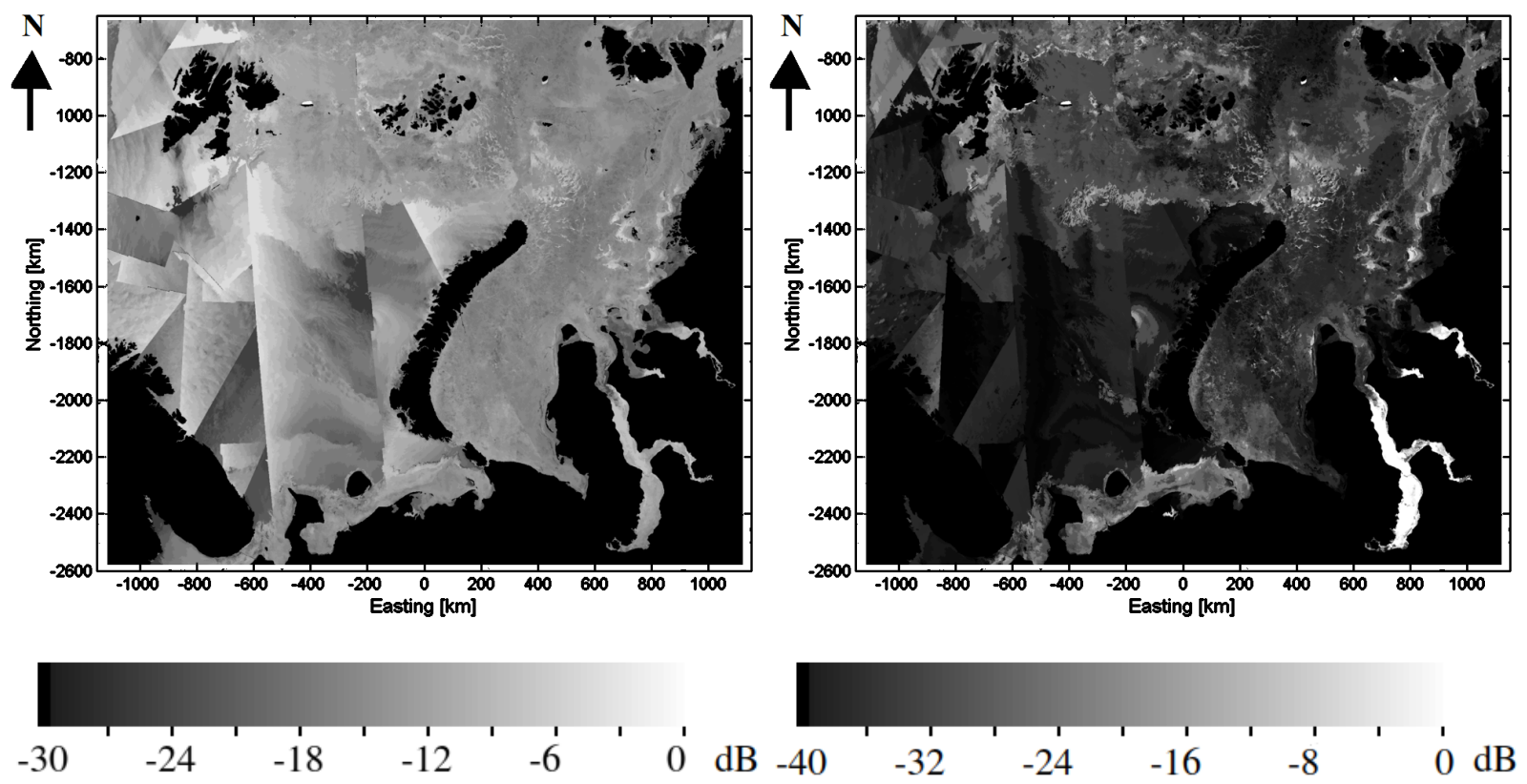

Figure 4. HH and HV mosaic $\sigma^{0}$ segment median of 21 Feb 2017. 
https://doi.org/10.5194/tc-2021-185

Preprint. Discussion started: 11 August 2021

(c) Author(s) 2021. CC BY 4.0 License.

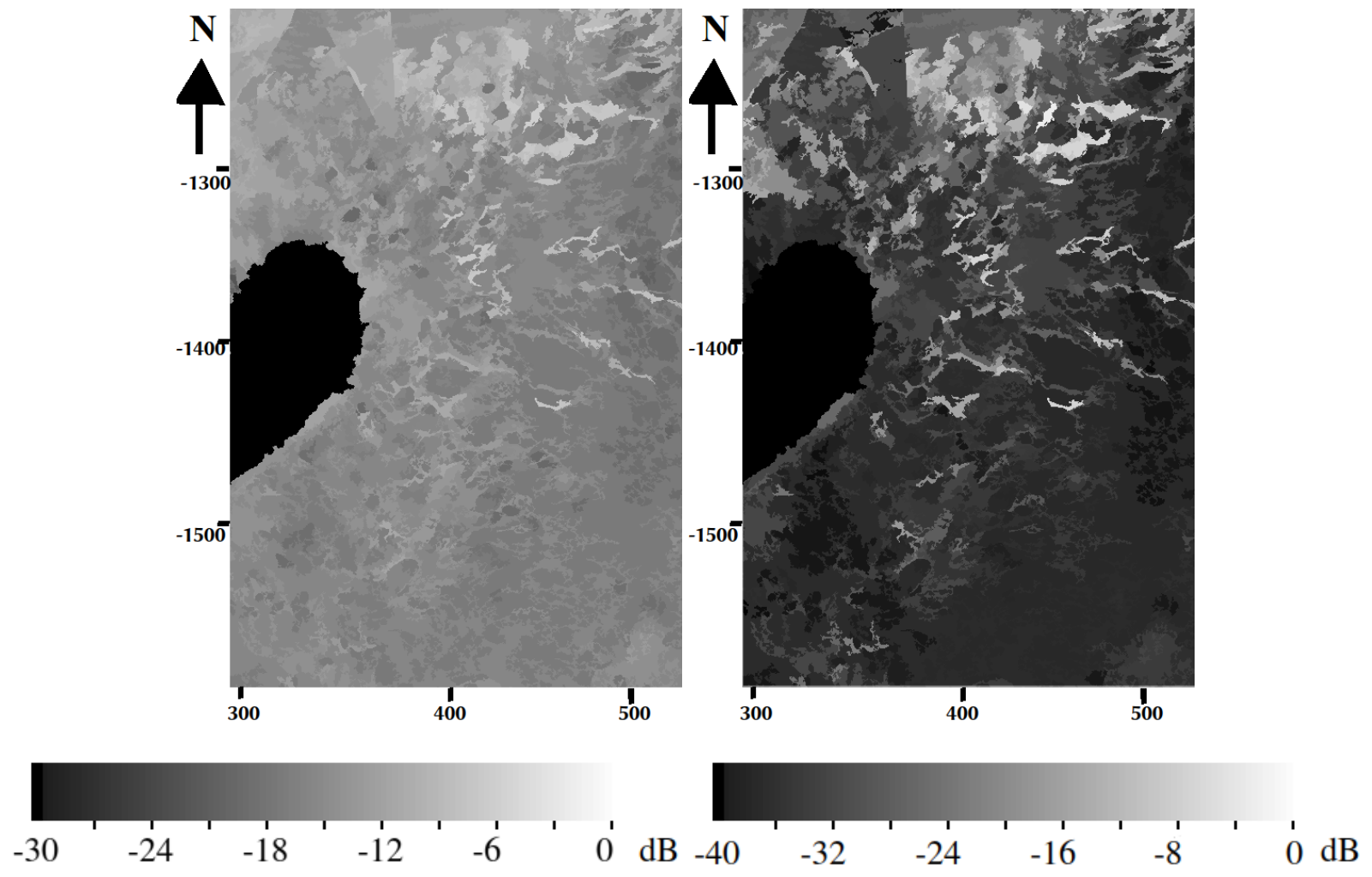

Figure 5. Cropped Area of the HH and HV segment median Images of Fig. 4. 
https://doi.org/10.5194/tc-2021-185

Preprint. Discussion started: 11 August 2021

(c) Author(s) 2021. CC BY 4.0 License.

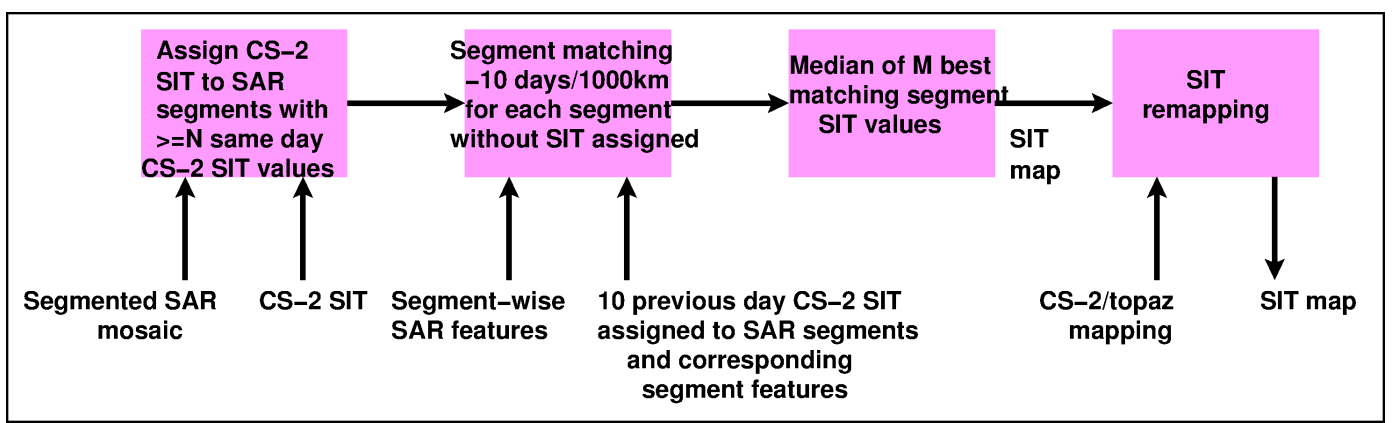

Figure 6. Algorithm block diagram. We have used $\mathrm{N}=9$ and $\mathrm{M}=5$ in this study.

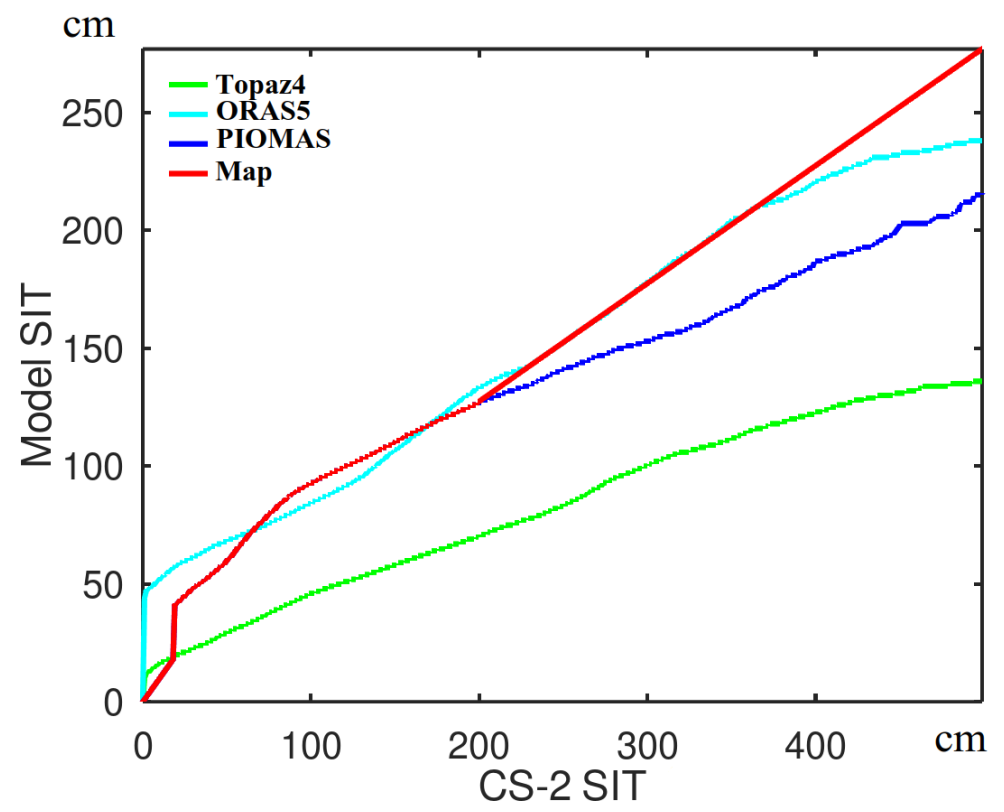

Figure 7. The CS-2/PIOMAS/ORAS5 SIT mapping based on histogram matching (red). Also the mappings corresponding to three ice models are shown. 

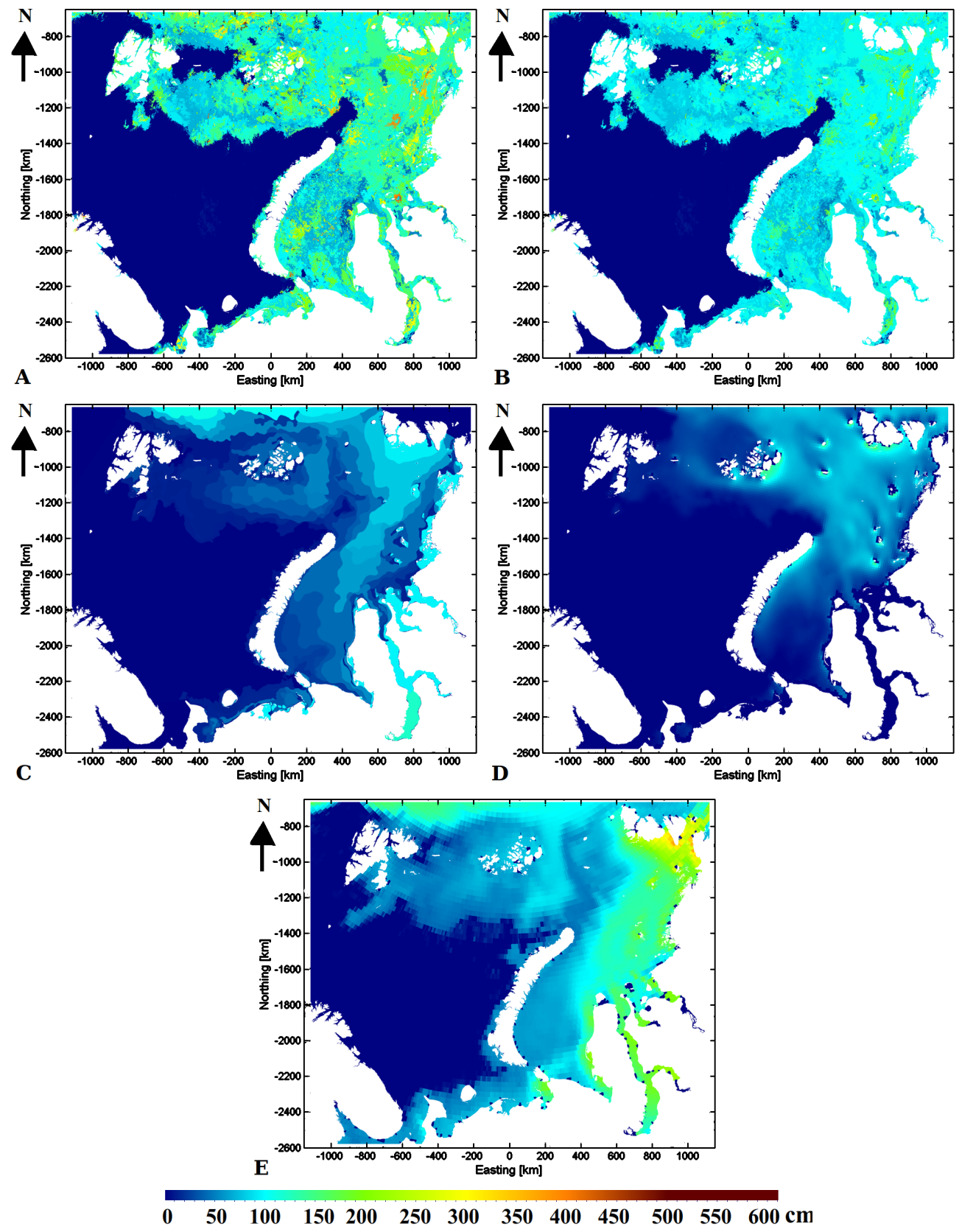

Figure 8. A: CS-2/S-1 SIT, B: remapped CS-2/S-1 SIT, C: AARI ice chart SIT, D: TOPAZ4 ice model renanalysis SIT and E: ORAS5 ice model SIT of 21 February 2021. 
https://doi.org/10.5194/tc-2021-185

Preprint. Discussion started: 11 August 2021

(c) Author(s) 2021. CC BY 4.0 License.

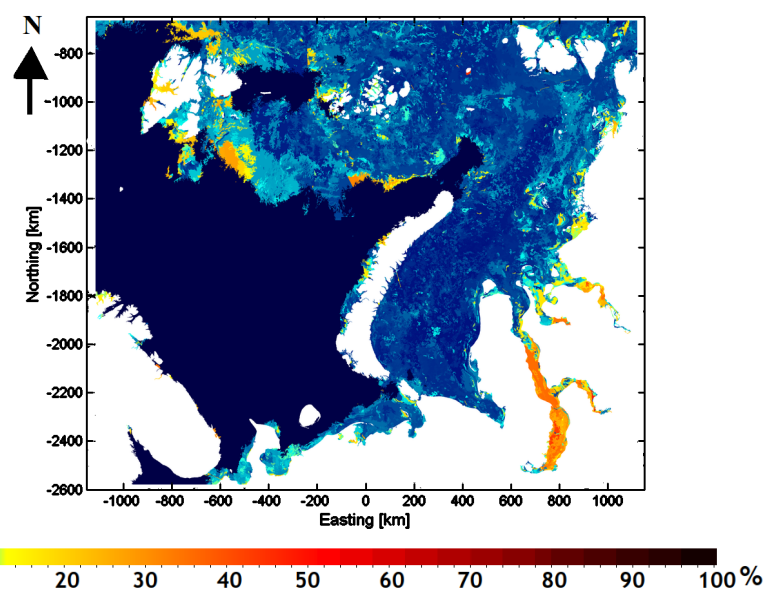

Figure 9. Median segment difference $(T)$ as a measure of uncertainty of the SIT estimates for 21 Feb 2017. The values of $T$ have been scaled to the range $0-100$, based on the variation of $T$ in the training data.

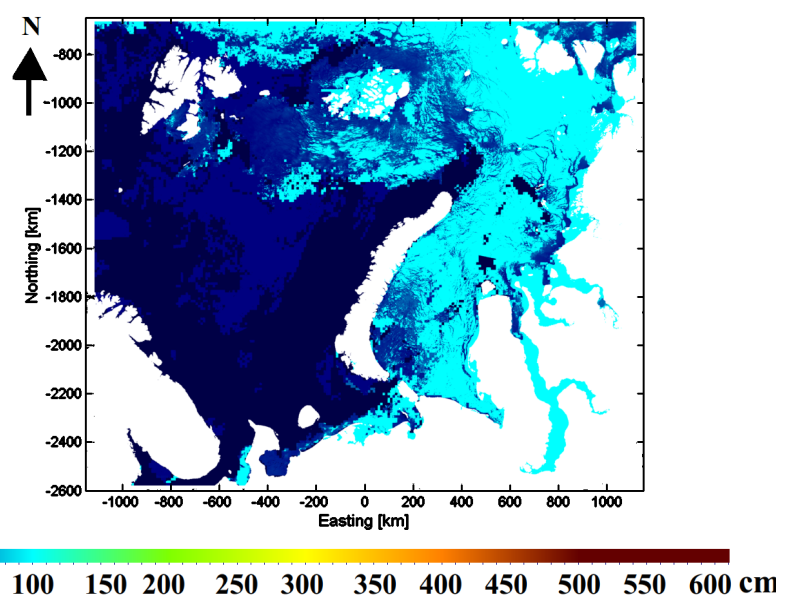

Figure 10. MODIS SIT collage based on two weeks MODIS SIT before 21 Feb 2017. The areas without data are indicated by black color and all the ice thicker than $50 \mathrm{~cm}$ is indicated by cyan color, corresponding to $100 \mathrm{~cm}$ in the colormap. 